\title{
DIMENSIONANDO O MERCADO PARA HIPOTECA REVERSA NO BRASIL
}

Igor Ferreira Rodrigo M. Pereira Mario Jorge Mendonça Beatriz Pinna
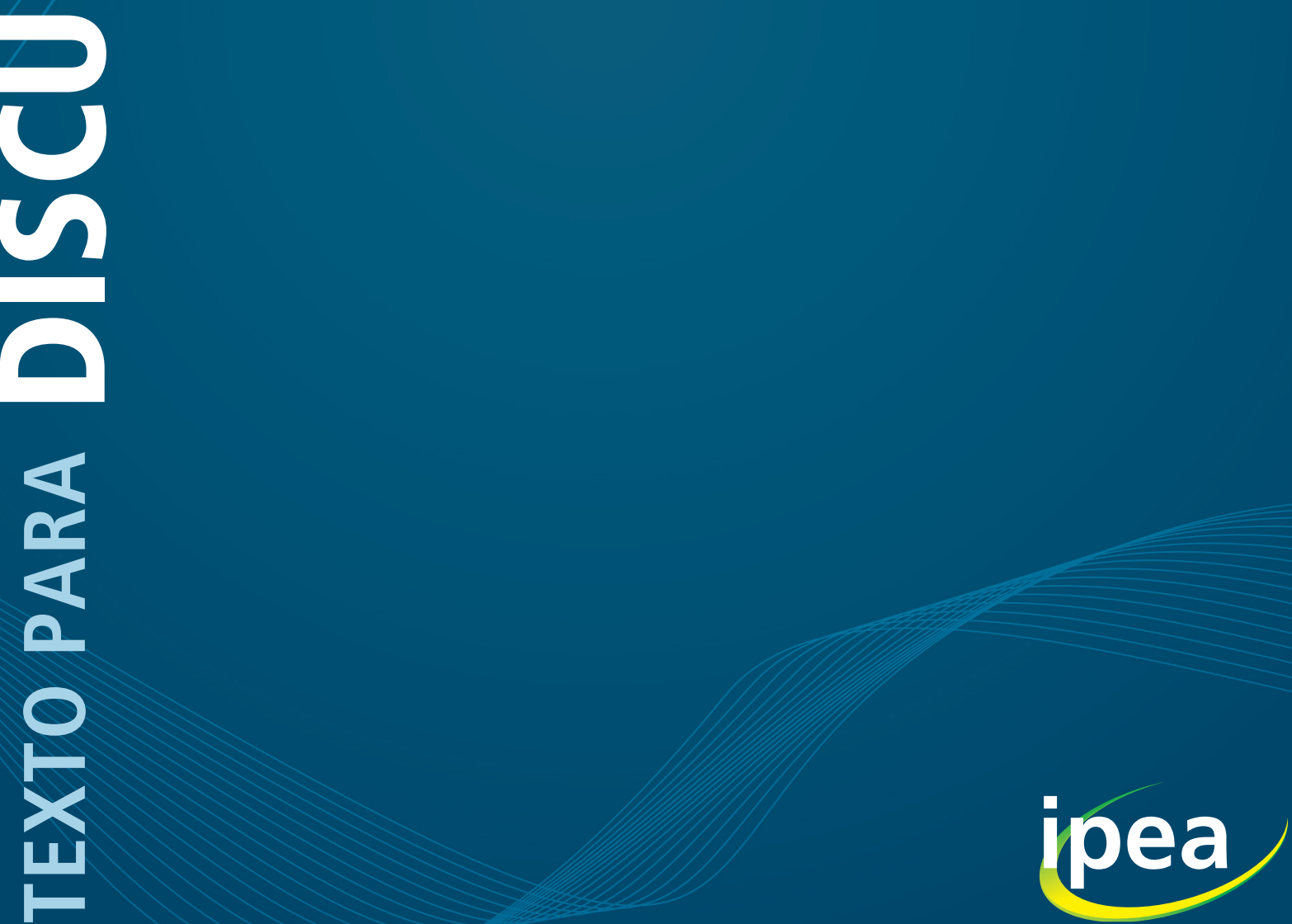



\section{TEXTO PARA DISCUSSÃO}

Brasília, dezembro de 2020

\section{DIMENSIONANDO O MERCADO PARA HIPOTECA REVERSA NO BRASIL}

Igor Ferreira'

Rodrigo M. Pereira²

Mario Jorge Mendonça ${ }^{3}$

Beatriz Pinna 4

1. Assistente de pesquisa na Diretoria de Estudos e Políticas Regionais, Urbanas e Ambientais (Dirur) do Ipea e professor do Instituto Federal do Piauí. E-mail: <igor.ferreira.n@gmail.com>.

2. Técnico de planejamento e pesquisa na Diretoria de Estudos Macroeconômicos (Dimac) do Ipea. Atualmente cedido ao Ministério da Economia (ME) como assessor especial da Secretaria de Política Econômica (SPE).E-mail: <rodrigo.pereira@ipea.gov.br>. 3. Técnico de planejamento e pesquisa na Dirur/lpea. Atualmente coordenador na Coordenação de Apoio e Articulação com o Poder Público (Coapp) da Dirur. E-mail: <mario.mendonca@ipea.gov.br>.

4. Assistente de pesquisa na Dirur/lpea.E-mail:<pinnarbeatriz@gmail.com>. 


\section{Governo Federal}

Ministério da Economia

Ministro Paulo Guedes

\section{ipea}

Fundação pública vinculada ao Ministério da Economia, o Ipea fornece suporte técnico e institucional às ações governamentais - possibilitando a formulação de inúmeras políticas públicas e programas de desenvolvimento brasileiros - e disponibiliza, para a sociedade, pesquisas e estudos realizados por seus técnicos.

\section{Presidente}

Carlos von Doellinger

Diretor de Desenvolvimento Institucional Manoel Rodrigues Junior

Diretora de Estudos e Políticas do Estado, das Instituições e da Democracia

Flávia de Holanda Schmidt

\section{Diretor de Estudos e Políticas}

Macroeconômicas

José Ronaldo de Castro Souza Júnior

Diretor de Estudos e Políticas Regionais, Urbanas e Ambientais

Nilo Luiz Saccaro Júnior

Diretor de Estudos e Políticas Setoriais de Inovação e Infraestrutura

André Tortato Rauen

\section{Diretora de Estudos e Políticas Sociais}

Lenita Maria Turchi

Diretor de Estudos e Relações Econômicas

e Políticas Internacionais

Ivan Tiago Machado Oliveira

Assessor-chefe de Imprensa

e Comunicação (substituto)

João Cláudio Garcia Rodrigues Lima

Ouvidoria: http://www.ipea.gov.br/ouvidoria

URL: http://www.ipea.gov.br

\section{Texto para Discussão}

Publicação seriada que divulga resultados de estudos e pesquisas em desenvolvimento pelo Ipea com o objetivo de fomentar o debate e oferecer subsídios à formulação e avaliação de políticas públicas.

(C) Instituto de Pesquisa Econômica Aplicada - ipea 2020

Texto para discussão / Instituto de Pesquisa Econômica Aplicada.- Brasília : Rio de Janeiro : Ipea, 1990-

ISSN 1415-4765

1.Brasil. 2.Aspectos Econômicos. 3.Aspectos Sociais. I. Instituto de Pesquisa Econômica Aplicada.

CDD 330.908

As publicações do Ipea estão disponíveis para download gratuito nos formatos PDF (todas) e EPUB (livros e periódicos).

Acesse: http://www.ipea.gov.br/portal/publicacoes

As opiniões emitidas nesta publicação são de exclusiva e inteira responsabilidade dos autores, não exprimindo, necessariamente, o ponto de vista do Instituto de Pesquisa Econômica Aplicada ou do Ministério da Economia.

É permitida a reprodução deste texto e dos dados nele contidos, desde que citada a fonte. Reproduções para fins comerciais são proibidas. 


\section{SUMÁRIO}

SINOPSE

ABSTRACT

1 INTRODUÇÃO

5 COMENTÁRIOS SOBRE A BASE DE DADOS E REPRESENTATIVIDADE AMOSTRAL ....24

6 COMENTÁRIOS FINAIS

APÊNDICE A

APÊNDICE B

APÊNDICE C

ANEXO A 



\section{SINOPSE}

Hipoteca reversa é um instrumento financeiro que permite que idosos proprietários de imóvel possam usufruir de uma renda adicional até o final da vida, quando o bem fica para a instituição financeira que propiciou o benefício. Com base nos dados da Pesquisa Nacional por Amostra de Domicílios (PNAD) Contínua de 2019, e considerando como público-alvo proprietários de imóveis que habitam sozinho o domićlio ou que residem com o cônjuge, este estudo tem como finalidade dimensionar o mercado para hipoteca reversa no Brasil. Um objetivo importante é identificar o volume mensal de crédito que entraria na economia. Nossa metodologia segue os seguintes passos. Estimamos uma regressão com a amostra não restrita da PNAD para determinação do preço do aluguel, obtendo o valor dos imóveis para a amostra restrita de elegíveis, por meio de uma regra sobre o valor predito do aluguel. Com o preço do imóvel, aplicamos um modelo que estima o benefício mensal da hipoteca reversa compatível com o equilíbrio financeiro e atuarial do sistema. Os resultados mostram que o benefício médio da hipoteca reversa é de $\mathrm{R}$ \$ 1,1 mil, enquanto o volume mensal de crédito passível de ser gerado é próximo a R 9 bilhóes. Tendo em vista a pressão existente sobre o sistema de previdência, do qual o Benefício de Prestação Continuada (BPC) faz parte, avaliamos o potencial de redução do dispêndio público com o BPC caso parte dos beneficiários desse programa optasse por aderir à hipoteca reversa.

Palavras-chave: hipoteca reversa; mínimos quadrados ponderados; perpetuidade; expectativa de vida; equilíbrio atuarial.

\section{ABSTRACT}

Reverse mortgage is a financial instrument that allows elderly homeowners to enjoy an additional income until the end of their lives, when the property is taken by the financial institution that provided the benefit. Based on data from the continuous PNAD of 2019 and considering the property owners who live alone at home or who live with their spouse as the potential market, this study aims to determine the size of the market for reverse mortgage in Brazil. One important goal is to identify the monthly volume of credit that would enter the economy. Our methodology has the following steps. We estimate a regression with PNAD's non-restricted sample to determine the rent price, obtaining the value of the properties for the restricted sample of eligible households, 
through a rule on the predicted value of the rent. With the predicted value of the property, we apply a model that estimates the monthly reverse mortgage benefit compatible with the financial and actuarial equilibrium of the system. The results show that the average reverse mortgage benefit is $\mathrm{R} \$ 1,100$ while the monthly credit volume that can be generated is close to $\mathrm{R} \$ 9$ billion. Considering the existing pressure on the social security system, in which the Continuous Benefit Program (BPC) is inserted, we evaluated the potential for reducing public spending with BPC in case part of the beneficiaries of this program chose to join the reverse mortgage.

Key words: reverse mortgage; weight least square; perpetuity; life expectance; actuarial equilibrium. 


\section{INTRODUÇÃO}

A hipoteca reversa é um mecanismo que permite que proprietários de imóveis recebam um empréstimo tendo como contrapartida sua propriedade imobiliária. Seu mercado potencial consiste em pessoas idosas que não têm desejo de deixar herança, gostariam de permanecer em suas residências até o fim da vida e, ao mesmo tempo, necessitam complementar a renda para sustentar um determinado padrão de consumo, muitas vezes, acrescido de grandes e inesperadas despesas médicas. À medida que o indivíduo envelhece, ele tem maiores restriçóes ao crédito, o que muitas vezes o faz vender sua residência quando se depara com gastos inesperados. A hipoteca reversa permite que o idoso permaneça no seu imóvel até o fim da vida, sem que haja perda de titularidade. Portanto, um mecanismo de hipoteca reversa tem o potencial de melhorar o bem-estar de idosos proprietários de imóvel e, simultaneamente, aumentar o volume de crédito agregado da economia.

A hipoteca reversa é um tema, particularmente, importante para o Brasil por pelo menos três motivos. Primeiro, o crédito privado é ainda baixo: 63,7\% do Produto Interno Bruto (PIB), contra $149 \%$ da média das economias avançadas. ${ }^{1}$ Mais crédito disponível na economia afeta positivamente as perspectivas de crescimento econômico do país. Segundo, o envelhecimento da população tende a ser potencialmente favorável à geração de um mercado para a hipoteca reversa, que deve se expandir ao longo do tempo. Terceiro, o sistema previdenciário público brasileiro está sujeito às limitações orçamentárias e à pressão de gerar condiçôes mínimas de subsistência a um segmento da população. A provisão de uma renda adicional via hipoteca reversa tende a aliviar essa pressão.

Diversos países têm sistemas de hipoteca reversa. O Canadá, por exemplo, tem um produto denominado CHIP reverse mortgage, oferecido pelo banco Home Equity Bank desde 1986. Recentemente, um produto concorrente foi lançado por outro banco, o Equitable Bank, para residentes das províncias de British Columbia, Alberta e Ontario. Em Hong Kong, o Hong Kong Mortgage Corporation, uma instituição pública, lançou um programa de hipoteca reversa em 2011. Nos Estados Unidos, o governo gerencia boa parte dos contratos de hipoteca reversa por meio de uma instituição denominada Federal House Administration, que é parte do Department of Housing

1. Dados do World Bank Open Data. Disponível em: <https://data.worldbank.org/>. 
and Urban Development (HUD). ${ }^{2}$ Esse sistema do governo, denominado home equity conversion mortgage (HECM), é responsável por aproximadamente $90 \%$ de todos os contratos de hipoteca reversa feitos nos Estados Unidos (Shan, 2011). Instituiçóes privadas também oferecem alternativas ao sistema governamental, mas têm uma fatia bem menor do mercado. ${ }^{3}$ De todo modo, a taxa de adesão norte-americana à hipoteca reversa é baixa. Nakajima e Telyukova (2017) apontam um percentual de 2,1\% dos idosos proprietários de imóveis nesse país optando por fazer uma hipoteca reversa em 2011. Carter e Miller (2017) citam uma estimativa de taxa de adesão à hipoteca reversa entre $2 \%$ e $3 \%$.

O Brasil ainda náo conta com nenhum sistema de hipoteca reversa. O tema é ainda pouco discutido, sendo que as referências na literatura econômica ainda são relativamente escassas. Exceção à regra para o Brasil é o trabalho de Caetano e Da Mata (2009) que descreve o sistema de hipoteca reversa e caracteriza seus principais riscos, buscando delimitar qual seria um eventual mercado desse instrumento financeiro no Brasil. Este estudo tem como principal objetivo dimensionar o mercado de hipoteca reversa no Brasil com base na estimativa do volume potencial de crédito gerado. A princípio, pode-se pensar que o volume gerado de crédito seria dado pelo valor de mercado dos imóveis da populaçáo elegível para hipoteca reversa, descontados certos custos de transação. No entanto, bem mais interessante é conhecer o volume de crédito gerado

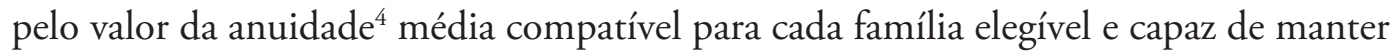
o equilíbrio financeiro e atuarial do sistema. Este artigo estima esse valor a partir da metodologia descrita a seguir.

2. Os quinze departamentos do governo nos Estados Unidos são as principais unidades operacionais do poder Executivo. São equivalentes aos ministérios no Brasil. 0 HUD se assemelharia a alguns ministérios da habitação ou das cidades que o Brasil já teve.

3. Por exemplo, a American Advisory Group oferece uma hipoteca reversa em que é possível tomar um empréstimo de 50\% a $66 \%$ do valor do imóvel, a uma taxa de juros em torno de $5 \%$ ao ano. Essa quantia pode vir na forma de um pagamento único ou em prestações mensais. Pode também ter a forma de uma linha de crédito. 0 valor da dívida aumenta com a taxa de juros e com alguns custos adicionais como taxas administrativas e seguros. Entre os seguros, há um com o HUD para que este assuma a dívida caso ela cresça acima do valor do imóvel (por exemplo, se o idoso vive por muito tempo). 0 empréstimo encerra-se quando o idoso morre (ou se viola os requisitos do contrato). Nesse caso, o idoso proprietário ou seus herdeiros podem pagar a dívida, ou $95 \%$ do valor estimado do imóvel (o que for menor). Ou simplesmente podem desistir do imóvel.

4. Anuidade é a renda recebida a cada período (por exemplo, mensalmente) durante um determinado tempo. 
Com base nos dados da Pesquisa Nacional por Amostra de Domicílios (PNAD) ${ }^{5}$ Contínua anual de 2019 sobre habitação, é possível estimar, por meio de um modelo econométrico, uma equação que relaciona o preço do aluguel com as características do imóvel. Tendo estimado o modelo, projetamos qual seria o preço do aluguel para todos os imóveis cuja população é elegível para a hipoteca reversa. A partir do valor estimado do aluguel, podemos obter por diferentes maneiras o valor do imóvel de cada família elegível, muito embora cada uma delas admita certo grau de arbitrariedade. A anuidade recebida por aquele que detém a hipoteca reversa é determinada pelo valor do imóvel, descontado os custos de transação, e pela expectativa de vida do participante na data do contrato.

Analisamos ainda como a hipoteca reversa pode ser usada para aliviar o gasto previdenciário. Mais especificamente, examinamos o caso do programa de Benefício de Prestação Continuada (BPC) inserido no nosso sistema de previdência propondo mecanismos para que beneficiário desse programa tenha incentivo a migrar para a hipoteca reversa. Verificamos que o volume de crédito estimado decorrente de uma mudança daqueles que recebem $\mathrm{BPC}$, mas que em média ganhariam $\mathrm{R} \$ 1,4$ mil caso optasse pela hipoteca, seria de $\mathrm{R} \$ 122$ milhóes.

Além desta introdução, este estudo está estruturado em mais cinco seções. A seção 2 descreve o sistema de hipoteca reversa dos Estados Unidos. A seçáo 3 apresenta a metodologia de estimação da anuidade média. Os resultados são apresentados na seção 4. Uma descrição da base de dados, bem como comentários de interesse acerca de sua representatividade amostral, aparece na seção 5. Por fim, a seção 6 conclui o trabalho.

\section{A HIPOTECA REVERSA NOS ESTADOS UNIDOS}

Nesta seção, vamos apresentar de forma mais detalhada como o sistema de hipoteca reversa nos Estados Unidos funciona. O sistema é voltado para proprietários de imóveis que tenham ao menos 62 anos de idade e residam em seu próprio imóvel. No caso de um casal aplicando conjuntamente, o cônjuge mais novo deve ter ao menos 62 anos. Se o imóvel ainda não estiver plenamente quitado, ele deve estar quase todo quitado, e o empréstimo deve ter uma provisão para quitar o imóvel. A hipoteca reversa permite que

5. 0 Instituto Brasileiro de Geografia e Estatística (IBGE) é o órgão responsável pela elaboração da PNAD. 
o proprietário aumente sua renda na forma de um empréstimo, o que pode amenizar o problema da restrição de renda em um período da vida no qual o indivíduo tem o seu capital humano depreciado.

O valor do empréstimo depende obviamente do valor da casa. Mas, no sistema HECM do governo, há um limite máximo para o valor da residência, atualmente de US\$ 727 mil. ${ }^{6}$ Se o imóvel for avaliado em um valor acima desse limite, o contrato pode ser feito, porém considerando o valor limite. As instituiçóes privadas oferecem o que se conhece como jumbo reverse mortgage loans que permite um empréstimo de valor maior que o limite federal, para imóveis mais caros. A quitação do empréstimo ocorre de forma lump sum, apenas quando ambos os cônjuges tenham morrido, ou caso decidam se mudar do imóvel (ou se houver alguma quebra de contrato pelo não cumprimento de suas cláusulas). Do valor obtido com a venda do imóvel, subtrai-se o valor do empréstimo, atualizado pelos juros e eventuais taxas. Em geral, o imóvel vale mais que o valor do empréstimo, e a diferença é do idoso ou de seus herdeiros. Ou seja, ao realizar um contrato de hipoteca reversa, o proprietário não está alienando totalmente o seu imóvel para o banco. Ele ainda detém a diferença entre seu valor de mercado e o valor do empréstimo. Portanto, é do seu interesse que a casa valha o máximo possível no momento de sua venda para a quitação do empréstimo. Esse desenho de contrato é muito importante para evitar o problema do perigo moral de má conservação e manutenção do imóvel.

Em alguns casos, entretanto, o imóvel pode valer menos que o valor do empréstimo no momento de sua quitação. Isso pode ser resultado de uma queda no preço do imóvel entre o momento em que a hipoteca reversa é feita e seu fim. Ou pode também ter um caráter atuarial: um idoso que tenha um tempo de vida muito acima da média. Para isso, todos os contratos de hipoteca reversa requerem um seguro obrigatório com o HUD. O órgão então usa os recursos dos prêmios desse seguro para cobrir a diferença.

Há basicamente três tipos de esquemas de pagamentos dos valores do empréstimo: i) pagamentos mensais fixos até que ambos os cônjuges tenham falecido (tenure reverse mortgage loan); ii) pagamentos mensais fixos por um período fixo (term reverse mortgage loan); e iii) linha de crédito flexível em que os idosos podem escolher os va-

6. Em valores de 2019.

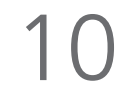


lores dos resgates, até um certo limite (line of credit). É possível também combinar os esquemas (i) e (iii) - modified tenure - e os esquemas (ii) e (iii) - modified term.

Em qualquer um dos esquemas de pagamento, se o idoso morre, a propriedade é vendida para pagar valor do empréstimo. Inclusive no caso (i). Com um pagamento mensal vitalício, se um idoso vive por muitos anos, é maior a possibilidade de que o valor dos pagamentos (e juros e taxas sobre a dívida formada) ultrapasse o valor do imóvel. Esse tipo de prejuízo é coberto pelo seguro obrigatório com o HUD e não via uma mutualizaçáo de riscos de mortalidade, com a apropriação dos imóveis de idosos que morrem pouco tempo depois de contratarem a hipoteca reversa. Nesses casos, o imóvel é vendido, paga-se o valor do empréstimo, e os herdeiros recebem o resíduo, que presumivelmente será quase todo o valor do imóvel.

Dois pontos aqui são importantes. Primeiro, o percentual de contratos de hipoteca reversa com pagamentos vitalícios do tipo tenure é baixo nos Estados Unidos, aproximadamente $10 \%$. Segundo, como o HUD não toma a casa dos idosos que morrem cedo para compensar os que recebem pagamentos do tipo tenure e vivem por muito tempo, esse tipo de eventualidade tem que ser coberto com prêmios de seguro relativamente altos, de modo que o HUD (e por tabela o pagador de impostos) náo tenha prejuízos. Isso passa uma percepçáo de que os custos de um contrato de hipoteca reversa são altos e de que o contrato não vale a pena. $\mathrm{Na}$ realidade, esses altos custos com seguro apenas compensam a inexistência da mutualização dos riscos. No entanto, em um sistema com mutualização de riscos, idosos que falecem prematuramente deixariam com o banco um imóvel muito mais valioso que as poucas anuidades recebidas, dando margem a uma judicialização excessiva por parte de herdeiros inconformados com a perda da herança e o pouco usufruto da hipoteca reversa por parte dos pais.

O sistema norte-americano de hipoteca reversa pode servir de modelo para um eventual sistema brasileiro, uma vez que tem atributos interessantes que, como já colocado abaixo, podem amenizar a restrição de renda na velhice assim como arrefecer o problema da previdência social que se encontra atualmente sobre pressão. Entretanto, há alguns aspectos de devem ser considerados.

Um desses aspectos é com relação à renda adicional que um idoso recebe do programa HECM, pois ela pode desqualificá-lo para receber alguns benefícios de assistên- 
cia social, tais como rendas suplementares e elegibilidade ao programa Medicaid (plano de saúde gratuito para indivíduos de baixa renda). Outro aspecto é que o Fair Housing Act, lei de 1968 implementada devido ao movimento de direitos civis, pró́be discriminação na venda, no aluguel e no financiamento de habitaçóes baseado em gênero (e também raça, religiáo etc.). Isso também afeta o mercado de hipoteca reversa, que fica impedido de prover condiçóes diferentes em um contrato de hipoteca reversa para dois idosos de sexos diferentes, embora a expectativa de vida da idosa mulher seja maior do que a do idoso homem (Shan, 2011). Portanto, consideram-se a ordenação jurídica e o contexto social brasileiros quando da elaboração da proposta para implantaçáo da hipoteca reversa no Brasil.

Um terceiro aspecto do sistema de hipoteca reversa americano são as altas taxas de falência técnica, que ocorre quando o idoso entra em default no pagamento das obrigaçôes do imóvel (seguro e impostos) e, ao mesmo tempo, já exauriu todos os recursos da hipoteca reversa. Em 2012, por exemplo, 9,4\% dos contratos HECM de hipoteca reversa estavam em falência técnica. Moulton, Haurin e Shi (2015) investigam o tema e, por meio de um modelo Probit, apontam quais as características do indivíduo são determinantes na probabilidade de falência técnica. Os autores mostram que, quanto maior é o percentual de fundos extraídos no primeiro mês de hipoteca reversa, maior é o risco de default. Um aumento de $10 \%$ no valor do resgate inicial está associado a um aumento de $0,62 \%$ na taxa de default. Negros e latinos têm taxas de default 2 pontos percentuais (p.p.) mais altas do que brancos. Para cada cem pontos adicionais de credit score, associa-se uma diminuiçâo de 2,3 p.p. na taxa de default. Além disso, indivíduos que tiveram problemas com o fisco anteriormente (tax liens) têm 1,1 p.p. a mais de taxa de default.

Davidoff e Wetzel (2014) identificam no sistema HECM de hipotecas reversas americanas uma espécie de seleção adversa geográfica, em que uma grande proporção de contratos foram originados em localidades onde os preços dos imóveis estavam mais inflados pela bolha especulativa que culminou na crise de 2008. Além disso, há uma grande proporçáa de contratos se iniciando próximos ao pico dos preços dos imóveis. Os autores entâo investigam se as famílias teriam conscientemente explorado essa oportunidade. Davidoff e Wetzel chegam a uma resposta negativa e fornecem evidência de que os contratantes de hipoteca reversa sob essas condições não fizeram uso do crédito de forma diferente dos demais. 


\section{METODOLOGIA}

Nesta seção, apresentamos a metodologia para estimação do potencial do mercado de hipoteca reversa no Brasil. Conforme dito na seção 1, é necessário saber o valor do estoque de imóveis residenciais que servem de moradia para a população elegível de pessoas idosas. No nosso caso, consideramos os seguintes público-alvo e condições da hipoteca reversa:

- famílias cujo chefe e o cônjuge têm mais de 60 anos;

- $\quad$ aqueles que são proprietários de imóveis quitados; $;^{7}$ e

- de modo a minimizar o problema do imóvel ser ou não objeto de herança para os herdeiros, decidimos adotar a hipótese conservadora restringindo a amostra para domicílios de imóvel próprio, com apenas um responsável ou com ele e o cônjuge, como sendo a população elegível para a hipoteca reversa. ${ }^{8}$

Nossa metodologia se compóe de duas partes. Na primeira delas, estimamos uma regressão para a determinação do preço do aluguel com a amostra da PNAD para os domicílios cujo imóvel é alugado. Nomeamos essa amostra como sendo a amostra não restrita. Com base nos coeficientes estimados que relacionam os efeitos das características do imóvel sobre o preço do aluguel, podemos projetar qual seria o preço do aluguel daqueles imóveis pertencentes ao grupo de elegíveis que, por sua vez, nomeamos por amostra restrita. Tendo projetado o preço do aluguel para os imóveis do grupo de elegíveis, pode-se estipular o valor de mercado por uma regra ad hoc.

Na segunda parte da metodologia, já de posse do valor do imóvel, aplicamos um modelo para precificar a perpetuidade compatível com o equilíbrio financeiro e atuarial para cada hipoteca reversa. A seguir, essas duas etapas são descritas.

7. Nos países onde existe hipoteca reversa, aceitam-se também imóveis prestes a serem quitados. No nosso caso, a PNAD disponibiliza informação sobre a quitação ou não do imóvel. Porém, quando ele não é quitado, não há informação sobre o percentual do imóvel que já foi pago.

8. Outros estudos não adotam esse filtro, isto é, não consideram quantos indivíduos residem no domicílio. Embora exista a possibilidade de que, apesar do responsável pelo domicílio residir sozinho, ele possa ter herdeiros. É mais plausível argumentar que o problema da herança diminui se os filhos não residem no mesmo domicílio que caso os filhos residissem no mesmo domicílio. 


\subsection{Determinação do valor do estoque de imóveis elegíveis para a hipoteca reversa}

Com base nos dados da PNAD Contínua Anual de 2019 (a primeira entrevista, a única que contém dados da habitação), estima-se um modelo econométrico para a determinação do preço do aluguel em funçáo das características do imóvel. Utilizamos os dados da pesquisa mais recente disponível, que atualmente é a de 2019. Portanto, trata-se de uma análise com dados de corte a preços de 2019. Na PNAD, há uma vasta quantidade de perguntas sobre as características da residência. Uma delas tem nesse estágio uma importância crucial. Trata-se da variável S01017, que pergunta se o domićlio é: i) próprio, de algum morador, já pago; ii) próprio, de algum morador, ainda pagando; iii) alugado; iv) cedido por empregador; v) cedido por familiar; vi) cedido de outra forma; e vii) outra condição. Filtramos inicialmente essa variável apenas para os domicílios alugados.

Estimamos uma regressão de mínimos quadrados ponderados tendo como variável dependente o valor do aluguel (variável S01019 da PNAD), enquanto as variáveis explicativas são aquelas que representam as características do domicílio. A regressão para o valor do aluguel a ser estimada é representada da seguinte forma:

$$
y_{i}=\alpha+\sum_{j=1}^{K} \beta_{j} x_{j i}+\sum_{j=K+1}^{S} \gamma_{j} z_{j i}+\varepsilon_{j i}
$$

em que $y_{i}$ é o $\log$ do valor do aluguel, ${ }^{9} \quad x_{j i}$ é a i-ésima observação da j-ésima variável quantitativas, enquanto $z_{j i}^{S}$ é a i-ésima observação da j-ésima variável categórica. As variáveis categóricas são transformadas em variáveis dummies. ${ }^{10}$ São três as variáveis quantitativas discretas usadas como regressores:

- número de cômodos no domicílio;

- número de dormitórios; ${ }^{11} \mathrm{e}$

- número de banheiros. ${ }^{12}$

9. A aplicação do log para o valor do aluguel evita que obtenhamos valores negativos para essa variável quando efetuarmos adiante a projeção de quanto seria o aluguel dos imóveis referentes dos domićlios do grupo de elegíveis.

10. Por exemplo, um domicílio situado no Rio de Janeiro entra com o atributo desse estado. Mais informações na tabela A.1 do apêndice $A$.

11. Número de cômodos servindo permanentemente como dormitório para os moradores do domicílio.

12. Quantos banheiros (com chuveiro ou banheira e vaso sanitário ou privada) de uso exclusivo dos moradores existem nesse domicílio, inclusive os localizados no terreno ou na propriedade?

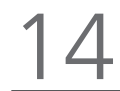


As variáveis qualitativas que foram transformadas em variáveis dummy são as seguintes:

- Unidade da Federação (UF);

- domicílio rural ou urbano;

- tipo de área (capital, região metropolitana, regiáo integrada de desenvolvimento econômico, ou resto da UF);

- tipo de domicílio (casa, apartamento, habitação em casa de cômodos, cortiço, ou cabeça de porco);

- material das paredes;

- material do telhado;

- material do piso;

- forma de abastecimento de água;

- disponibilidade de reservatório de água;

- destino do esgoto;

- destino do lixo;

- disponibilidade de energia elétrica; e

- disponibilidade de telefone fixo.

Em seguida, tomamos os coeficientes estimados na equação (1) para fazer uma previsão de qual seria o valor do aluguel dos imóveis pertencentes ao grupo dos elegíveis à hipoteca reversa. Tendo predito qual seria o valor do aluguel, é possível calcular o valor do imóvel por pelo menos duas maneiras.

$$
\hat{y}_{i}=\hat{\alpha}+\sum_{j=1}^{K} \hat{\beta}_{j} x_{j i}+\sum_{j=K+1}^{S} \hat{\gamma}_{j} z_{j i}
$$

em que as estimativas dos coeficientes e os valores preditos do aluguel são denotados por chapéus, enquanto $x_{j i}$ é a i-ésima observação da j-ésima variável discreta da amostra de elegíveis elegível e $z_{j i}$ é a i-ésima observação da j-ésima variável dummy, também da população elegível. 
O valor do imóvel a partir do preço do aluguel pode ser obtido por pelo menos duas maneiras. Primeiro, podemos supor que a renda anual do aluguel de um imóvel equivale a 0,5\% de seu valor. Ou seja, a hipótese é a de que são necessários vinte anos de aluguéis (240 meses) somados para se chegar ao valor do imóvel. ${ }^{13}$ Com isso, obtemos uma estimativa do valor do imóvel de todos os domicílios pesquisados na PNAD. Esquemas de valoração mais complexos podem ser calculados, uma vez que a PNAD disponibiliza o número de cômodos de cada imóvel. Segundo, existem séries históricas para a relação entre preço do aluguel e o preço do imóvel para as principais cidades do Brasil. ${ }^{14}$ Assim, o valor do imóvel é obtido por meio da razão entre o preço do aluguel e a relação preço do aluguel/valor do imóvel.

\subsection{Modelo de precificação da anuidade em uma hipoteca reversa}

Antes de explicitarmos o método com que iremos estimar a anuidade recebida pelo optante da hipoteca reversa, é necessário considerar as hipóteses nas quais o nosso modelo se assenta. A modalidade de hipoteca reversa que analisaremos é a do tipo tenure, ou seja, pagamentos mensais fixos até que ambos os cônjuges tenham falecido (tenure reverse mortgage loan). No nosso modelo, essa abordagem pode ser utilizada sem dificuldade para tratar uma modalidade variante na qual os recebimentos mensais ocorrem por um período fixo (term reverse mortgage loan). Cada contrato de hipoteca reversa está associado a uma conta na qual a cada período pode-se acessar o saldo devedor líquido da hipoteca reversa definido pelo empréstimo (valor recebido na data do contrato) atualizado pelos juros e eventuais taxas menos o valor do investimento atualizado pelo valor de mercado. Assim, o contrato pode ser interrompido antes que ambos os cônjuges tenham morrido, podendo a quitação do empréstimo ser feita quando o detentor da hipoteca reversa decidir se mudar do imóvel. Quando o valor do imóvel se situa acima do empréstimo, a diferença é do idoso, quando este decide se mudar; ou de seus herdeiros, quando ocorre falecimento do titular.

13. Trata-se obviamente de uma simplificação, uma vez que imóveis maiores tendem a ter aluguéis como uma proporção menor de seu valor, se comparados a imóveis pequenos.

14. A Fundação Instituto de Pesquisas Econômicas da Universidade de São Paulo (Fipe/USP) elabora diversos índices relacionados com o mercado imobiliário entre os quais a relação entre o preço do aluguel e o valor do imóvel para diversas cidades do Brasil. Para mais informações, acesse o link disponível em: <https://bit.ly/3fE6bq7>. 
Feitas as primeiras consideraçóes, passemos a discorrer sobre o modelo que usaremos para precificar a anuidade do contrato de hipoteca reversa compatível com o equilíbrio atuarial e financeira do sistema. De início, cabe chamar a atenção para o fato de que a hipoteca reversa guarda certa relação com o modelo de previdência. Neste, os fundos têm o objetivo de garantir ao investidor uma renda com caráter previdenciário a ser recebida após o período de atividade laboral. Diferentemente, no modelo de hipoteca reversa, o fluxo é invertido. A retirada para o participante ocorre antecipadamente, pois a entidade patrocinadora somente poderá dispor do valor do investimento futuramente após o término do contrato.

Tomando como referência a terminologia usada nos modelos de previdência, pode-se enquadrar o instrumento de hipoteca reversa como sendo uma modalidade que mistura os conceitos de benefício definido (BD) e de contribuição definida (CD). Isto é, o valor do benefício é determinado, exclusivamente, pelo valor acumulado da reserva, que nesse caso é o valor do imóvel na data da contratação da hipoteca reversa, caracterizando o período de acumulaçáo como o que é observado na modalidade CD. Os participantes receberão o benefício enquanto vivos, fazendo com o que o risco seja compartilhado entre os contratos.

Dessa forma, a hipoteca reversa é o pagamento periódico de um benefício, que aqui denominamos benefício de hipoteca reversa (BHR), a partir da data de assinatura do contrato, ocasião em que o participante tem direito ao recebimento de uma renda mensal, enquanto pelo menos um dos cônjuges esteja vivo. O BHR para o indivíduo é determinado pelo valor do imóvel (VI) e pelo fator (perpetuidade), que transforma a reserva em benefício pago enquanto um dos membros esteja vivo, no início do contrato, baseado em uma taxa de juros $i$ e na probabilidade de sobrevivência a partir da data do contrato. Nesse contexto, a fórmula para o cálculo do benefício é dada por:

$$
\begin{aligned}
& B H R=\frac{V I}{F(i,)}, \\
& F(i,)=\sum_{k=0}^{\infty}\left(\frac{1}{1+i}\right)^{k} p_{k}^{t},
\end{aligned}
$$

sendo $p_{k}^{t}$ a probabilidade de sobrevivência entre $t$ e $k$ (Dickson, Hardy e Waters, 2013). 
O BHR também estará disponível para um casal. Nesse caso, os contratos para hipoteca reversa são do tipo last-survivor, em que o contrato permanece ativo até que pelo menos um esteja vivo. Apesar de ser possível modelar esse tipo de contrato em tempo contínuo (Jevtić e Hurd, 2017), neste trabalho, a probabilidade de que o contrato permaneça ativo é modelada por meio de um processo markoviano em tempo discreto, semelhante ao proposto por Ji et al. (2011) e Zadeh e Amirhashchi (2018). É razoável imaginar que um casal que vive na mesma residência está exposto a fatores ambientais muito semelhantes e que, por isso, há uma dependência entre as probabilidades de mortalidade do casal. $\mathrm{O}$ modelo proposto permite, assim como abordado por Ji e Rui (2019), implementar a dependência entre a vida do casal; no entanto, por simplificação, consideramos a independência entre as probabilidades de morte do casal.

Nesse caso, é mais difícil obter a tábua de vida diretamente, sendo solucionada neste trabalho por meio de aproximaçôes probabilísticas. Considere um casal formado por um homem de idade ih e uma mulher de idade im e que iniciou um contrato de hipoteca reversa. Seja $q_{h}^{t}$ a probabilidade de morte do homem no instante e $q_{m}^{t}$ a probabilidade de morte da mulher no instante $t$. Sabe-se que o BHR será pago enquanto qualquer um dos dois estiver vivo e sabendo que a morte dos dois ocorre de forma independente, a probabilidade do fim do contrato no instante, isto é, caso nenhum dos dois esteja vivo, pode ser obtido por meio do método de simulação de Monte Carlo de duas distribuiçôes Bernoulli independentes com parâmetros, tal que:

$$
\begin{aligned}
& B_{h}^{t} \sim \operatorname{Bern}\left(q_{h}^{t}\right) \text { e } B_{m}^{t} \sim \operatorname{Bern}\left(q_{m}^{t}\right), \\
& B_{\text {casal }}^{t}=\operatorname{Máx}\left(\prod_{k=0}^{t} G\left(B_{h}^{i h+k}\right), \prod_{k=0}^{t} G\left(B_{m}^{i m+k}\right)\right), \\
& S_{\text {casal }}^{t}=\sum_{i=1}^{n} B_{\text {casal }}^{t,(i)}, \\
& q_{\text {casal }}^{t}=\frac{s_{\text {casal }}^{t}-S_{\text {casal }}^{t-1},}{S_{\text {casal }}^{t-1}}
\end{aligned}
$$


sendo $\mathrm{G}(\mathrm{X})$ a função indicadora de vida $(\mathrm{X}=0), S_{\text {casal }}^{t}$ o valor simulado de casais vivos no instante $t$ e $q_{\text {casal }}^{t}$ a probabilidade aproximada de morte do casal no instante e o número de simulações. Dessa forma, sabendo a idade do casal e a tábua de vida, calcula-se a função expressa em (4). Neste estudo, utilizamos a tábua de vidas RP-2000 (Actuaries, 2000) e $\mathrm{n}=10^{6}$. As expectativas de vida para algumas idades considerando os contratos de idosos desacompanhados por sexo e de casais com mesma idade, propostas pelas equaçóes (5), (6), (7) e (8), estão apresentadas no anexo A ao final do texto. De maneira geral, percebe-se que a expectativa de vida do casal é, em média, superior às expectativas individuais. Os resultados encontrados estão de acordo com o que é apresentado por Baek et al. (2013), o que indica que utilizar a tábua de vida do membro com menor idade superestima o valor do benefício de hipoteca reversa.

Para simplificar a modelagem, sem que ocorra a perda de generalidade, são considerados intervalos anuais entre os pagamentos, a atualização da reserva e a probabilidade de morte no modelo. A taxa de juros de atualizaçáo da reserva individual (RI) e a taxa de juros do investimento adotada são de $4 \%$ ao ano.

Cabe destacar a importância da nossa metodologia para prefixação da perpetuidade. Por exemplo, nos Estados Unidos, quando o titular da hipoteca reversa e o seu cônjuge já tiverem falecido, o imóvel é vendido, paga-se o valor da dívida, e, se houver sobra, é dos herdeiros. Se houver falta, a diferença é coberta por um seguro. No nosso trabalho, isso não está sendo feito. Não existe seguro e não há necessidade. Temos, portanto, um equilíbrio atuarial e financeiro. Esse equilíbrio baseia-se em uma mutualização dos riscos (risk pooling), em que eventuais perdas da instituiçấo credora em contratos com indivíduos que morrem muito velhos são compensados com os contratos de indivíduos que morrem cedo.

\section{APRESENTAÇÃO DOWS RESULTADOS}

Nesta seção, apresentamos os resultados obtidos com a metodologia descrita na seção 3 . Adicionalmente, propomos empregar a hipoteca reversa como instrumento de política pública, visando à mitigação do gasto do governo em programas sociais. Nesse sentido, estamos falando mais especificamente do caso do BPC e como podemos usar a hipoteca reversa de modo a incentivar a migração do beneficiário desse programa para esse tipo 
de hipoteca. Portanto, doravante, serão mostrados os números da hipoteca reversa que também guardam relação com o BPC obtidos com base na nossa metodologia.

Inicialmente, mostramos, na tabela A.1 do apêndice A, os resultados da estimação da equação (1), baseada no método de mínimos quadrados ponderados, de modo a atender ao plano amostral da PNAD no qual cada registro está associado a um determinado peso. O significado das variáveis utilizadas aparece no quadro A.1 do anexo A. Com relação ao tipo de domicílio, foram selecionados para o estudo apenas domicílios do tipo casa ou apartamento. $\mathrm{O}$ modelo proposto para o valor do aluguel obteve uma medida de qualidade $\mathrm{R}^{2}=64,83 \%$ e apresentou resíduos com distribuição aproximadamente T-Student.

Ainda na tabela A.1 do apêndice A, verificamos a robustez das estimativas dos coeficientes de regressão, estimando um modelo alternativo, com resíduos T-Student, semelhante a Osorio (2019). A diferença média entre os coeficientes estimados pelo modelo com resíduos gaussianos e o com resíduos T-Student foi de -0,017. Os valores dos coeficientes estimados nos dois modelos são apresentados nas colunas 2 e 6 da tabela A.1, e sua diferença é apresentada na coluna 7. Percebe-se que os parâmetros com menor significância estatística apresentaram as maiores diferenças entres as estimativas de cada modelo. Dessa forma, apesar da violação do pressuposto de normalidade dos resíduos, prosseguiu-se com o modelo com resíduos gaussianos. Os valores estimados e os gráficos de ajustes com os quantis teóricos das duas distribuiçóes estão apresentados também no apêndice A. Dado que a variável dependente preço do aluguel é sempre positiva, aplicamos a transformação log. Isso evita que sejam gerados valores preditos negativos cabendo notar que o preço do aluguel deve ser sempre positivo. ${ }^{15}$

A seguir, com base nos parâmetros estimados, projetamos o preço do aluguel para os imóveis cujos domicílios pertencem ao grupo de elegíveis. Supomos que o valor do aluguel mensal equivale a $0,5 \%$ do valor de mercado do imóvel. Com base nessa regra, obtemos o valor do imóvel para o grupo de elegíveis. O valor de cada imóvel entra na equação (3) de modo a gerar o BHR compatível com o equilíbrio financeiro e atuarial do sistema.

15. Alguns imóveis têm características tão ruins que o valor predito para seu aluguel seria negativo. A rigor, essas famílias estariam excluídas de um eventual sistema de hipoteca reversa. Isso porque há certos custos que são fixos (por exemplo, custos administrativos, o custo de valoração do imóvel etc.), de modo que não há viabilidade econômica para hipotecas reversas de imóveis com valor muito baixo. 
Os números iniciais são mostrados na tabela 1 . Nela, temos, nas colunas de 1 a 3, o tipo de contrato discriminado, se desacompanhado ou casal, o número de registros na PNAD e, com base nesse último e nos pesos dos domicílios, o total geral para o Brasil de imóveis elegíveis para a hipoteca reversa. A coluna 4 mostra a expectativa de vida média levando em consideração a existência do cônjuge quando for o caso. As colunas 5 e 7 ilustram as informações mais importantes que são o valor médio do BHR e o volume total de crédito gerado na economia. Conforme pode ser visto, o volume potencial de crédito é de aproximadamente $\mathrm{R} \$ 8,7$ bilhóes. Considerando apenas o contrato para elegíveis desacompanhados, alcançamos algo próximo a $\mathrm{R} \$ 5,0$ bilhóes.

TABELA 1

Valores estimados para o BHR por tipo de contrato, segundo número de participantes

\begin{tabular}{|c|c|c|c|c|c|c|}
\hline Tipo de contrato & $\begin{array}{c}\text { Registros } \\
\text { (2) }\end{array}$ & $\begin{array}{c}\text { Número de } \\
\text { domicílios } \\
\text { (3) }\end{array}$ & $\begin{array}{c}\text { Expectativa } \\
\text { de vida } \\
\text { (4) }\end{array}$ & $\begin{array}{l}\text { Hipoteca reversa } \\
\text { valor mensal } \\
\text { (R\$) } \\
\text { (5) }\end{array}$ & $\begin{array}{l}\text { Valor } \\
\text { do imóvel } \\
\text { (R\$) } \\
\text { (6) }\end{array}$ & $\begin{array}{c}\text { Volume mensal } \\
\text { gerado } \\
(\mathrm{R} \$) \\
(7)\end{array}$ \\
\hline Casal & 7.254 & 3.320 .329 & 20,34 & 1.107 & 170.051 & 3.674.817.417 \\
\hline Desacompanhado & 8.385 & 4.080 .242 & 14,85 & 1.238 & 133.649 & 5.052 .927 .646 \\
\hline
\end{tabular}

Elaboração dos autores.

Esses valores mensais gerados são apenas uma estimativa do potencial de mercado. Há na realidade dois redutores que fariam com que o volume mensal gerado na economia fosse bem mais modesto. Por um lado, os valores dos empréstimos em hipotecas reversas nunca correspondem ao valor total do imóvel. Isso porque existem custos administrativos e juros incidentes sobre o valor da dívida acumulada até o momento do falecimento do idoso e término do contrato. Nos Estados Unidos, por exemplo, boa parte dos contratos tem essa relação valor do empréstimo/valor do imóvel em torno de 0,6 a 0,7 (Shan, 2011). Por outro lado, nos países em que há hipoteca reversa, as taxas de adesão são relativamente baixas, entre $2 \%$ e 3\% do total de domicílios elegíveis. Aplicando-se uma taxa de adesão de 2,5\% e uma relação valor do empréstimo/valor do imóvel de 65,0\%, o volume mensal gerado pela hipoteca reversa na modalidade tenure no Brasil seria de $\mathrm{R} \$$ 141.825.857,00 mensais, o que equivale a $\mathrm{R} \$ 1,7$ bilhão anual aproximadamente.

A multiplicação da coluna 3 pela coluna 6 na tabela 1 nos dá o valor do patrimônio imobiliário total desse subgrupo populacional de idosos proprietários de imóveis. Os valores são $\mathrm{R} \$ 564,6$ bilhóes para idosos casais, e $\mathrm{R} \$ 545,3$ bilhôes para idosos sós (solteiros ou viúvos). O valor total agregado é de R\$1,1 trilhão. Aplicando os mesmos 
redutores de taxa de adesão e razão valor empréstimo/imóvel de 2,5\% e 65,0\% respectivamente, temos um valor de $\mathrm{R} \$ 18$ bilhóes. Esse seria o total de crédito que seria injetado na economia como resultado de um programa de hipoteca reversa com desembolsos do tipo linha de crédito. $\mathrm{O}$ valor equivale a um aumento de $0,39 \%$ do total de crédito privado disponível no país (aproximadamente R \$ 4,65 trilhóes em 2019).

O objetivo nesse estudo vai além do dimensionamento do mercado da hipoteca reversa no Brasil. Queremos investigar a possibilidade do emprego da hipoteca reversa como meio de diminuir a pressão sobre o sistema previdenciário, tendo em mente que programas como o $\mathrm{BPC}^{16}$ fazem parte dele. Assim, uma política que incentivasse a diminuição do gasto com o BPC concomitantemente com o surgimento e posterior ampliação do mercado de hipoteca reversa seria muito bem-vinda. De modo a acessarmos a viabilidade dessa política, temos que considerar o que os números dizem. Para tal, é necessário conhecer qual o tamanho da população que recebe o BPC e que se enquadra também no grupo de elegíveis. A tabela 2 mostra os mesmos indicadores da hipoteca reversa, discriminando entre o total de elegíveis e desses, aqueles que recebem BPC. Algumas informações chamam atenção. Primeiro, há um total de 372 mil domicílios elegíveis à hipoteca reversa que recebem BPC. Ou seja, 5,3\% dos pouco mais de 7 milhôes de domicílios elegíveis. Segundo, o percentual de desacompanhados (solteiros e viúvos) é um pouco maior nesse subgrupo recebedor de BPC: $61,42 \%$, contra 54,80\% no grupo geral de elegíveis.

TABELA 2

Quantitativo de domicílios elegíveis por tipo de contrato, segundo existência do BPC e número de participantes

\begin{tabular}{|c|c|c|}
\hline Tipo & Casal & Desacompanhado \\
\hline Geral & $3.176 .582(45,20 \%)$ & $3.851 .422(54,80 \%)$ \\
\hline $\mathrm{BPC}$ & $143.747(38,58 \%)$ & $228.820(61,42 \%)$ \\
\hline
\end{tabular}

Elaboração dos autores.

A tabela 3 apresenta a média de idade dos domicílios elegíveis por estado civil e por participação ou não no BPC. Tanto para os casais quanto para os desacompanha-

16. Este benefício é do Sistema Único de Assistência Social gerido pelo Instituto Nacional do Seguro Social (INSS) e previsto na Lei Orgânica da Assistência Social (Loas). Consiste em uma renda de um salário mínimo para idosos e deficientes que não possam se manter e não possam ser mantidos por suas famílias. Considera-se idoso quem tem mais de 65 anos e o deficiente que não possui capacidade para a vida independente e para inserção ou reinserção social e no mercado de trabalho. 
dos, a média de idade dos participantes com contratos em domicílios que recebem BPC é superior à dos demais. Além disso, os contratos com menor idade média são os do tipo geral formado por casais, com 70,21 anos de idade.

O volume total mensal de crédito potencial para aqueles inclusos no programa BPC é de cerca de R $\$ 284$ milhóes. Observa-se, entretanto, que o BHR mensal estimado para aquele que recebe o BPC situa-se abaixo de R 1 mil que é o valor do próprio BPC. A questáo entáo que se coloca é como tirar proveito da hipoteca reversa de modo a diminuir os gastos com o BPC? Usamos a tabela 3 para responder essa questão: a média da expectativa de vida daqueles que recebem BPC é menor, indicando que a idade média daqueles inclusos no BPC é maior.

TABELA 3

Média das idades dos participantes por tipo de contrato, segundo existência do BPC e número de participantes

\begin{tabular}{lcc}
\hline Tipo & Casal & Desacompanhado \\
\hline Geral & 70,21 & 71,92 \\
BPC & 72,55 & 72,44 \\
\hline
\end{tabular}

Elaboração dos autores.

Sendo assim, os contratos do BPC são em média menos longos pela combinação de participantes mais velhos e maior percentual de contratos desacompanhados.

TABELA 4

Valores estimados para o BHR por tipo de contrato, segundo existência do BPC

\begin{tabular}{lcccccr}
\hline Tipo de contrato & Registros & $\begin{array}{c}\text { Número de } \\
\text { domicílios }\end{array}$ & $\begin{array}{c}\text { Expectativa } \\
\text { de vida }\end{array}$ & $\begin{array}{c}\text { Hipoteca reversa } \\
\text { valor mensal } \\
(\mathrm{R} \$)\end{array}$ & $\begin{array}{c}\text { Valor } \\
\text { imóvel } \\
(\mathrm{R} \$)\end{array}$ & $\begin{array}{c}\text { Volume mensal } \\
\text { gerado } \\
(\mathrm{R} \$)\end{array}$ \\
(1) & $(2)$ & $(3)$ & $(4)$ & $(5)$ & $17)$ & $(7)$ \\
\hline Geral & 14.864 & 7.028 .005 & 17,38 & 762 & 152.920 & 8.443 .703 .197 \\
BPC & 775 & 372.566 & 15,98 & 762 & 94.534 & 284.041 .865 \\
\hline
\end{tabular}

Elaboração dos autores.

As linhas 2 e 3 da tabela 5 se referem aos elegíveis que participam do BPC, discriminando, respectivamente, entre aqueles que receberiam o BHR com valor abaixo ou acima de R\$ 1 mil; valor de referência do BPC. Vejamos como podemos gerar mecanismos de incentivo para fazer com que aquele que está no BPC decida-se migrar 
para a hipoteca reversa. Cabe a ressalva que os valores que aparecem nas colunas 4, $5 \mathrm{e}$ 6 referem-se aos valores médios desses indicadores.

Vejamos agora o caso do elegível que recebe o BPC e que poderia receber um BHR de R \$ 1.492. Suponha ainda que o governo oferecesse como subsídio mais $\mathrm{R} \$$ 500 como incentivo a migrar para a hipoteca reversa. Haveria ganho para ambos, pois o governo que paga pelo BPC R \$ 1 mil economizaria $\mathrm{R} \$ 500$, enquanto aquele que recebe o BPC passará a receber algo próximo a $\mathrm{R} \$ 2$ mil. Estratégia semelhante poderia ser aplicada àqueles que ganhariam menos, mas próximo a $\mathrm{R} \$ 1 \mathrm{mil}$.

TABELA 5

Valores estimados para o BHR por tipo de contrato, segundo existência do BPC

\begin{tabular}{|c|c|c|c|c|c|c|}
\hline Tipo de contrato & Registros & $\begin{array}{c}\text { Número de } \\
\text { domicílios } \\
\text { (3) }\end{array}$ & $\begin{array}{l}\text { Expectativa } \\
\text { de vida } \\
\text { (4) }\end{array}$ & $\begin{array}{l}\text { Hipoteca reversa } \\
\text { valor mensal } \\
\text { (R\$) } \\
\text { (5) }\end{array}$ & $\begin{array}{l}\text { Valor } \\
\text { imóvel } \\
(R \$) \\
(6)\end{array}$ & $\begin{array}{l}\text { Volume mensal } \\
\text { gerado } \\
(\mathrm{R} \$) \\
(7)\end{array}$ \\
\hline Geral & 14.864 & 7.028 .005 & 17,38 & 1.201 & 152.920 & 8.443 .703 .197 \\
\hline $\mathrm{BHR}<\mathrm{R} \$ 1 \mathrm{mil}$ & 654 & 290.402 & 16,92 & 556 & 76.090 & 161.480 .388 \\
\hline $\mathrm{BHR}>\mathrm{R} \$ 1 \mathrm{mil}$ & 121 & 82.165 & 12,68 & 1.492 & 159.719 & 122.561 .477 \\
\hline
\end{tabular}

Elaboração dos autores.

Obs.: BPC R\$ 1 mil indica lares com benefício BHR superior a R\$1 mil.

Em mercados como os Estados Unidos, a modalidade de desembolsos do tipo linha de crédito é a mais popular. Uma das principais justificativas para sua popularidade é que com ela o idoso é capaz de lidar com grandes gastos de saúde inesperados - por exemplo, uma cirurgia. Um pagamento mensal do tipo tenure não é adequado a essas situaçóes. O Brasil, entretanto, tem uma rede de proteção social ao idoso relativamente mais abrangente do que o sistema dos Estados Unidos, com instituiçóes como o Sistema Único de Saúde (SUS). Pode-se pensar, portanto, que hipotecas reversas do tipo tenure têm um potencial de serem mais populares por aqui.

\section{COMENTÁRIOS SOBRE A BASE DE DADOS E REPRESENTATIVIDADE AMOSTRAL}

A base de dados utilizada para este estudo são os microdados da PNAD Contínua/ IBGE para o ano de 2019. A pesquisa tem por objetivo produzir indicadores para acompanhar as flutuaçóes trimestrais e a evolução, a médio e longo prazos, da força 
de trabalho e outras informações necessárias para o estudo e desenvolvimento socioeconômico do país, segundo o IBGE. A PNAD Contínua possui cobertura em todo o território nacional, excluídas as áreas com características especiais, e seus resultados são divulgados para o Brasil, Grandes Regiōes, Unidades da Federação (UFs), vinte regiôes metropolitanas e a regiáo integrada de desenvolvimento da grande Teresina. Sua população-alvo é constituída por todas as pessoas moradoras em domicílios particulares permanentes da área de abrangência da pesquisa.

A pesquisa é realizada por meio de uma amostra probabilística de domicílios, extraída de uma amostra mestra de setores censitários, de forma a garantir a representatividade dos resultados para os diversos níveis geográficos citados. O plano amostral adotado na PNAD Contínua é conglomerado em dois estágios de seleção com estratificação das unidades primárias de amostragem (UPAs). A PNAD Contínua possui um esquema de rotação, no qual um domicílio é entrevistado durante cinco trimestres, uma vez a cada trimestre. A amostra total domicílios é coletada ao final do período de três meses para serem produzidos os indicadores e estimativas necessários.

Conforme descrito, a PNAD Contínua é uma pesquisa com amostra complexa, já que incorpora conglomeração e estratificação. Dessa maneira, faz-se necessário o uso de métodos adequados que consideram as características do plano amostral de forma a obter estimativas corretas para as estatísticas de interesse.

Nesse estudo, o software R, em conjunto com o pacote survey, foi utilizado para a incorporação do desenho amostral da pesquisa no processo de estimação, modelagem estatística e também para obtenção das estatísticas descritivas.

Os dados referentes à habitação, às características gerais dos moradores em domicílios particulares permanentes e à força de trabalho são investigados na primeira visita dos agentes do IBGE, e são esses dados que são utilizados neste trabalho para o ano de 2019.

A representatividade desses dados da PNAD se dá apenas em nível nacional. Qualquer tentativa de obter resultados para um nível de desagregaçáo maior (região, UF, região metropolitana etc.) poderá levar à obtenção de estimativas com elevado nível de imprecisão, devido ao desenho amostral da pesquisa. 
Isso pode ser ilustrado por meio da tabela 6. Nela mostramos as estatísticas para o BHR mensal médio, estimado por meio do modelo apresentado na seção 3.1, para as categorias de domicílios segundo recebimento do BPC. Conforme pode ser visto, a categoria que recebe BPC e que receberia um BHR acima de $\mathrm{R} \$ 1$ mil apresenta um coeficiente de variação ${ }^{17}(\mathrm{CV})$ de $5,1 \%$ para a média do BHR. Isso implica que a análise do BHR para tal categoria em um nível de desagregação espacial maior teria como consequência um CV acima de 5,0\%, o que indicaria um nível de incerteza não desejado para fins de representatividade dos parâmetros amostrais.

TABELA 6

BHR mensal

\begin{tabular}{lccccc}
\hline Categoria & Registros & Domicílios & $\begin{array}{c}\text { Média } \\
(\mathrm{R} \$)\end{array}$ & $\begin{array}{c}\text { Desvio-padrão } \\
(\mathrm{R} \$)\end{array}$ & $\begin{array}{c}\text { CV } \\
(\%)\end{array}$ \\
$(1)$ & $(2)$ & $(3)$ & $(4)$ & $25)$ & $(6)$ \\
\hline Geral & 14.864 & 7.028 .005 & 1.201 & 11,07 & 2,1 \\
BHR< R\$ 1 mil & 654 & 290,402 & 556 & 73,28 & 2,0 \\
BHR $>$ R \$ 1 mil & 121 & 82,165 & 1.492 & 5,1 \\
\hline
\end{tabular}

Elaboração dos autores.

As medidas de precisão para as estimativas apresentadas na tabela 6 não consideram o erro proveniente do modelo de regressão, e, com relação ao plano amostral da PNAD, seguem procedimento de aproximação da variância do estimador por meio da linearização de Taylor, com maiores detalhes apresentados em Freitas e Antonaci (2014).

\section{COMENTÁRIOS FINAIS}

A hipoteca reversa é um instrumento de garantia de crédito que tem um potencial de melhorar o bem-estar de um segmento da população e de injetar crédito privado na economia. Idosos em geral têm rendas mais baixas e maiores restrições ao crédito, porém mais capital imobiliário acumulado. A hipoteca reversa permite que esse estoque de capital imobiliário seja usado como provisão adicional de recursos, que pode ter um papel importante na suavização da trajetória de consumo ao longo da vida. Ao mesmo tempo, ela permite que esses idosos permaneçam em seus imóveis até o fim da vida.

17. Razão entre o desvio-padrão e a média. 
Há, portanto, uma evidente possibilidade para melhoras no sentido de Pareto, quando alguns indivíduos têm ganhos sem que ninguém tenha nenhuma perda de bem-estar. ${ }^{18}$

Por sua vez, a hipoteca reversa funciona como uma expansão nas garantias ao crédito privado. E o Brasil é um país com necessidades urgentes de mais crédito. A razão crédito privado/PIB brasileira de $63,7 \%$ é baixa mesmo para os padrōes de um país de renda média ou média alta. $\mathrm{O}$ crédito privado é o grande propulsor de uma economia capitalista, e não foi uma coincidência que o período recente de maior crescimento da economia brasileira, na segunda metade dos anos 2000, foi também o período de maior expansão do crédito privado no país.

Esse artigo utiliza os dados da PNAD Contínua Anual de 2019 para dar algumas respostas quantitativas fundamentais a respeito da implementação de uma hipoteca reversa brasileira. Qual seria o aumento total no crédito privado no Brasil resultante da implementaçáo de um sistema de hipoteca reversa com desembolsos do tipo linha de crédito? Qual seria o total de pagamentos mensais de benefícios de hipoteca reversa em um sistema com desembolsos do tipo tenure? Haveria alguma possibilidade de redução de gastos previdenciários tais como o BPC de famílias que deixariam situaçóes de vulnerabilidade com os pagamentos mensais da hipoteca reversa?

Vimos que em um cenário de taxa de adesão de $2,5 \%$ e razão média do valor do empréstimo/valor do imóvel de 65,0\%, ${ }^{19}$ haveria um acréscimo de $\mathrm{R} \$ 18$ bilhóes no crédito privado na economia, o que corresponde a um aumento de $0,39 \%$. Sob o mesmo cenário, mas com desembolsos do tipo tenure, teríamos um volume total de pagamentos mensais de R \$ 141,8 milhôes, ou R \$ 1,7 bilhão anuais. Encontramos também condiçôes bastante plausíveis para uma diminuição de gastos previdenciários, sem que haja grande comprometimento nos incentivos de adesão ao sistema por parte de famílias elegíveis.

Por fim, cabe pontuar algumas questóes importantes acerca da hipoteca reversa e que devem ser objeto de discussão caso o governo tenha a intenção de realmente

18. Na hipótese de não haver herdeiros para a população de elegíveis. Há ainda a hipótese de que os herdeiros teriam que gastar menos recursos para complementar a renda dos pais.

19. Dado do Banco Central do Brasil. 
implementar esse instrumento na economia brasileira. Primeiro, considerando a taxa de envelhecimento da população no Brasil e a crise fiscal, a hipoteca reversa tende a se firmar cada vez mais como um instrumento a ser considerado. Assim, um estudo acerca do potencial de crescimento do mercado de hipoteca reversa no Brasil seria bem-vindo. Segundo, levando em consideração o contexto brasileiro e a cultura jurídica, esta é ainda pouco propensa a tratar as econômicas de modo isento e náo poucas vezes introduz argumentação de cunho social, quando avalia algum ponto mais sensível.

Desse modo, conforme colocado ao final da seção 2, além do risco atuarial que consideramos na nossa análise sobre a hipoteca reversa, existe o risco de default por parte do beneficiário e que não foi tratado nesse estudo. No entanto, o risco de default deve merecer atençáo quando da formulação dos mecanismos de incentivo desse instrumento.

\section{REFERÊNCIAS}

ACTUARIES, S. The RP-2000 mortality tables. [s.1.]: Actuaries Society, 2000. Disponível em: <https://bit.ly/2KvV7j7>.

BAEK, H. Y.; LEE, S.; LEE, H. An analysis of a reverse mortgage using a multiple life model. Korean Journal of Applied Statistics, v. 26, n. 3, p. 531-547, 2013.

CAETANO, M.; DA MATA, D. Hipoteca reversa. Rio de Janeiro: Ipea, 2009. (Texto para Discussão, n. 1380).

CARTER, G.; MILLER, J. The HECM program in a snapshot. Cityscape: A Journal of Policy Development and Research, v. 19, n. 1, 2017.

DAVIDOFF, T.; WETZEL, J. Do reverse mortgage borrowers use credit ruthlessly? Vancouver: University of British Columbia, 2014. (University of British Columbia Working Paper).

DICKSON, D. C. M.; HARDY, M. R.; WATERS, H. R. Actuarial mathematics for life contingent risks. Cambridge: Cambridge University Press, 2013.

FREITAS, M. P. S.; ANTONACI, G. A. Amostra Mestra 2010 e Amostra da PNAD Contínua. Rio de Janeiro: IBGE, 2014.

JEVTIC, P.; HURD, T. R. The joint mortality of couples in continuous time. Insurance: mathematics and economics, v. 75, p. 90-97, 2017.

MOULTON, S.; HAURIN, D. R.; SHI, W. An analysis of default risk in the Home Equity Conversion Mortgage (HECM) program. Journal of Urban Economics, v. 90, p. 17-34, 2015. 
NAKAJIMA, M.; TELYUKOVA, I. Reverse mortgage loans: a quantitative analysis. The Journal of Finance, v. 72, Issue 2, p. 911-950, 2017.

OSORIO, F. Heavy: robust estimation using heavy-tailed distributions. [s.l.]: [s.l.], 2019. (R package version 0.38.196). Disponível em: <https://bit.ly/3fsXK0C>. Acesso em:

SHAN, H. Reversing the trend: the recent expansion of the reverse mortgage market. Real Estate Economics, v. 39, n. 4, p. 743-768, 2011.

ZADEH, A. H.; AMIRHASHCHI, S. Modelling joint lifetimes of couples by using bivariate phase-type distributions. arXiv preprint arXiv:1806.10111, 2018. 


\section{APÊNDICE A}

\section{RESULTADOS DA REGRESSÃO}

TABELA A.1

Estimativas do modelo de regressão do modelo para previsão do aluguel, considerando resíduos gaussianos e com distribuição T-Student

\begin{tabular}{|c|c|c|c|c|c|c|}
\hline Parâmetro & Estimativa & Erro-padrão & Valor $t$ & $\operatorname{Pr}(>|t|)$ & $\begin{array}{c}\text { Estimativa } \\
\text { modelo T }\end{array}$ & Diferença \\
\hline (Intercept) & 5,9102 & 0,0446 & 132,568 & 0,000 & 5,9161 & $-0,0059$ \\
\hline S01005 & 0,0971 & 0,0035 & 27,45 & 0,000 & 0,0884 & 0,0087 \\
\hline S01006 & 0,0331 & 0,0081 & 4,0967 & 0,000 & 0,0456 & $-0,0125$ \\
\hline S01011A & 0,2289 & 0,0113 & 20,3009 & 0,000 & 0,2369 & $-0,008$ \\
\hline S010012 & 0,2656 & 0,0296 & 8,9639 & 0,000 & 0,2382 & 0,0274 \\
\hline S01002novo & $-0,0579$ & 0,0061 & $-9,5411$ & 0,000 & $-0,0425$ & $-0,0154$ \\
\hline S01003novo & 0,0633 & 0,0085 & 7,4826 & 0,000 & 0,0636 & $-0,0003$ \\
\hline S01004novo & $-0,0834$ & 0,0079 & $-10,4939$ & 0,000 & $-0,1127$ & 0,0293 \\
\hline S010092 & $-0,1305$ & 0,011 & $-11,8116$ & 0,000 & $-0,1156$ & $-0,0149$ \\
\hline S01012Anovo & $-0,0647$ & 0,0055 & $-11,7232$ & 0,000 & $-0,0603$ & $-0,0044$ \\
\hline S01013novo & $-0,0726$ & 0,017 & $-4,2794$ & 0,000 & $-0,0722$ & $-0,0004$ \\
\hline S010142 & $-0,4979$ & 0,1321 & $-3,7704$ & 0,002 & $-0,3034$ & $-0,1945$ \\
\hline S010222 & $-0,1447$ & 0,0131 & $-11,0542$ & 0,000 & $-0,1506$ & 0,0059 \\
\hline V10222 & $-0,2495$ & 0,0322 & $-7,7443$ & 0,000 & $-0,2235$ & $-0,026$ \\
\hline V10232 & $-0,1792$ & 0,0197 & $-9,1106$ & 0,000 & $-0,1793$ & 0,0001 \\
\hline V10233 & $-0,2972$ & 0,0357 & $-8,3269$ & 0,000 & $-0,2698$ & $-0,0274$ \\
\hline V10234 & $-0,3098$ & 0,0158 & $-19,6327$ & 0,000 & $-0,3025$ & $-0,0073$ \\
\hline UF12 & $-0,1148$ & 0,0488 & $-2,3534$ & 0,0186 & $-0,1422$ & 0,0274 \\
\hline UF13 & $-0,0986$ & 0,0428 & $-2,305$ & 0,0212 & $-0,0895$ & $-0,0091$ \\
\hline UF14 & $-0,0219$ & 0,0452 & $-0,4843$ & 0,6282 & $-0,0165$ & $-0,0054$ \\
\hline UF15 & 0,0023 & 0,0377 & 0,0619 & 0,9507 & 0,0225 & $-0,0202$ \\
\hline UF16 & $-0,0984$ & 0,0793 & $-1,2416$ & 0,2144 & $-0,0521$ & $-0,0463$ \\
\hline UF17 & $-0,0539$ & 0,0396 & $-1,3597$ & 0,174 & $-0,0287$ & $-0,0252$ \\
\hline UF21 & $-0,1905$ & 0,0377 & $-5,058$ & 0,000 & $-0,1788$ & $-0,0117$ \\
\hline UF22 & $-0,3593$ & 0,0444 & $-8,0929$ & 0,000 & $-0,3062$ & $-0,0531$ \\
\hline UF23 & $-0,2981$ & 0,0333 & $-8,9502$ & 0,000 & $-0,2854$ & $-0,0127$ \\
\hline UF24 & $-0,288$ & 0,0442 & $-6,5159$ & 0,000 & $-0,3047$ & 0,0167 \\
\hline UF25 & $-0,3633$ & 0,0381 & $-9,5451$ & 0,000 & $-0,3107$ & $-0,0526$ \\
\hline \multirow[t]{2}{*}{ UF26 } & $-0,1917$ & 0,0373 & $-5,1351$ & 0,000 & $-0,1851$ & $-0,0066$ \\
\hline & & & & & & (Continua \\
\hline
\end{tabular}


Texto para

Discussão

2620 Dimensionando o Mercado para Hipoteca Reversa no Brasil

\begin{tabular}{|c|c|c|c|c|c|c|}
\hline Parâmetro & Estimativa & Erro-padrão & Valor $t$ & $\operatorname{Pr}(>|t|)$ & $\begin{array}{l}\text { Estimativa } \\
\text { modelo T }\end{array}$ & Diferença \\
\hline UF27 & $-0,346$ & 0,0351 & $-9,8619$ & 0,000 & $-0,3269$ & $-0,0191$ \\
\hline UF28 & $-0,3236$ & 0,0377 & $-8,5847$ & 0,000 & $-0,3099$ & $-0,0137$ \\
\hline UF29 & $-0,2692$ & 0,0412 & $-6,5297$ & 0,000 & $-0,2566$ & $-0,0126$ \\
\hline UF31 & $-0,0581$ & 0,0335 & $-1,7342$ & 0,0829 & $-0,0181$ & $-0,04$ \\
\hline UF32 & $-0,1075$ & 0,0349 & $-3,0821$ & 0,0021 & $-0,0732$ & $-0,0343$ \\
\hline UF33 & 0,1968 & 0,0349 & 5,6355 & 0,000 & 0,2125 & $-0,0157$ \\
\hline UF35 & 0,305 & 0,0395 & 7,7271 & 0,000 & 0,3391 & $-0,0341$ \\
\hline UF41 & 0,1536 & 0,0324 & 4,7436 & 0,000 & 0,1763 & $-0,0227$ \\
\hline UF42 & 0,3197 & 0,0319 & 10,0101 & 0,000 & 0,3608 & $-0,0411$ \\
\hline UF43 & 0,2516 & 0,0331 & 7,6 & 0,000 & 0,2795 & $-0,0279$ \\
\hline UF50 & 0,196 & 0,0367 & 5,3393 & 0,000 & 0,2019 & $-0,0059$ \\
\hline UF51 & 0,2671 & 0,0446 & 5,9917 & 0,000 & 0,2777 & $-0,0106$ \\
\hline UF52 & 0,0073 & 0,0338 & 0,2145 & 0,8302 & 0,0279 & $-0,0206$ \\
\hline UF53 & 0,1196 & 0,0373 & 3,2027 & 0,0014 & 0,1393 & $-0,0197$ \\
\hline
\end{tabular}

Elaboração dos autores.

GRÁFICO A.1

Quantis teóricos dos resíduos para os modelos do aluguel
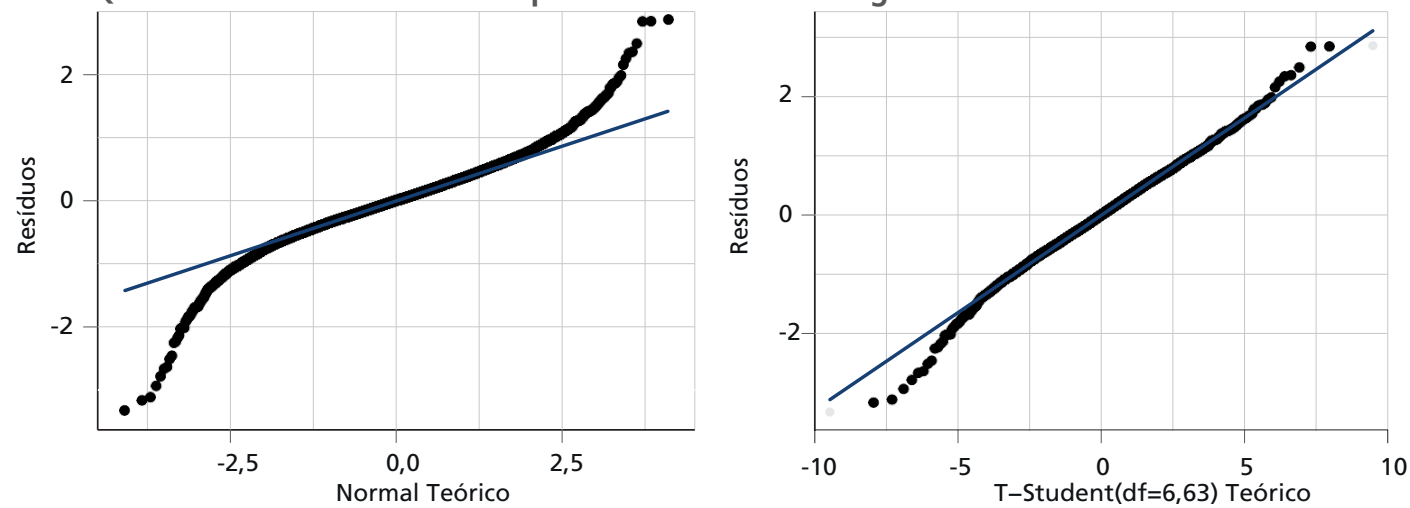

Elaboração dos autores. 


\section{APÊNDICE B}

\section{GRÁFICOS PARA A HIPOTECA REVERSA}

GRÁFICO B.1

Distribuição para os resultados de dimensionamento da hipoteca reversa

B.1A - Distribuição observada para log do BHR dos domicílios elegíveis encontrados na PNAD por tipo de contrato

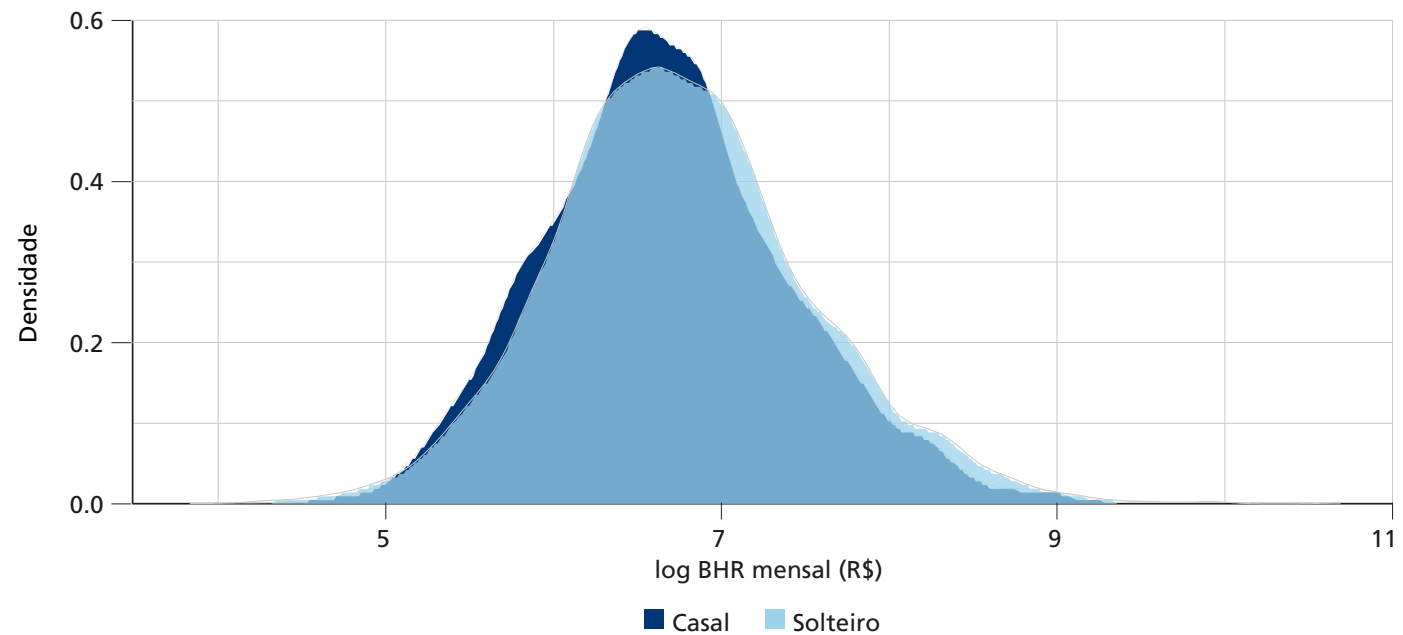

Elaboração dos autores.

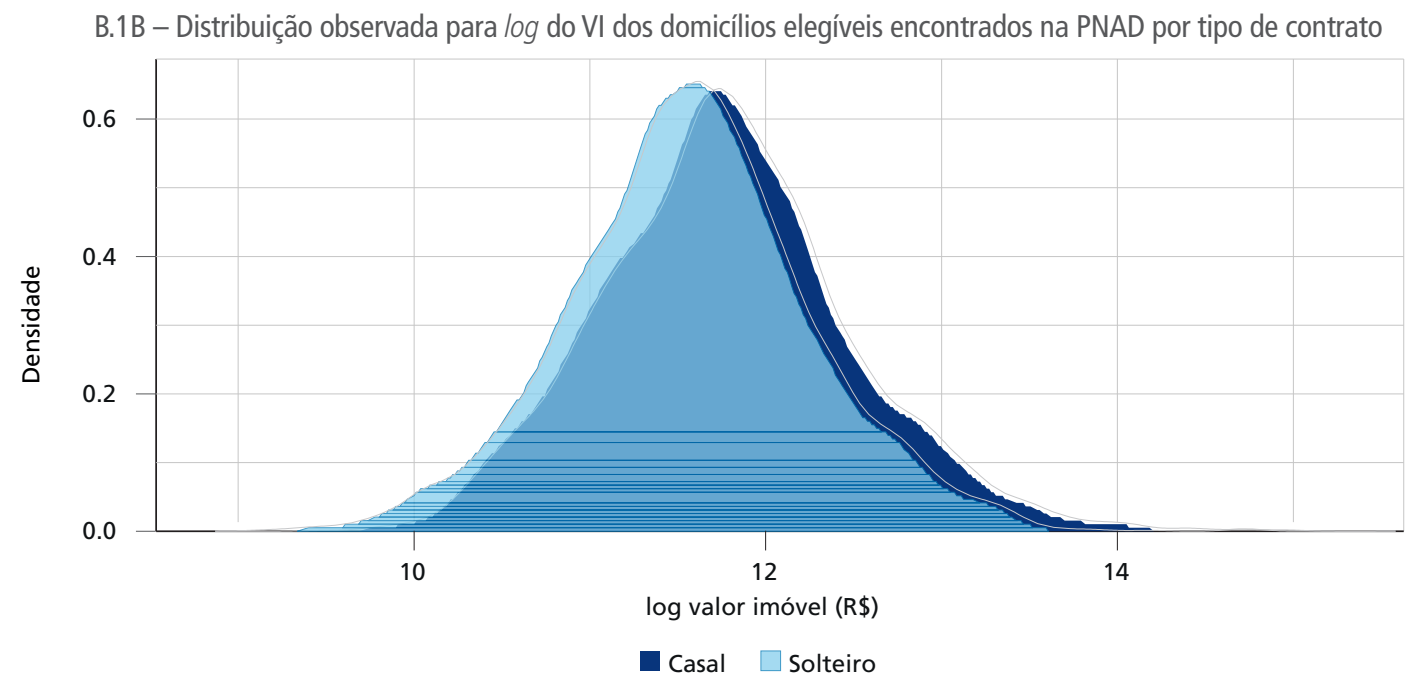

Elaboração dos autores. 
B.1C - Distribuição observada para o tempo esperado do contrato dos domicílios elegíveis encontrados na PNAD por tipo de contrato

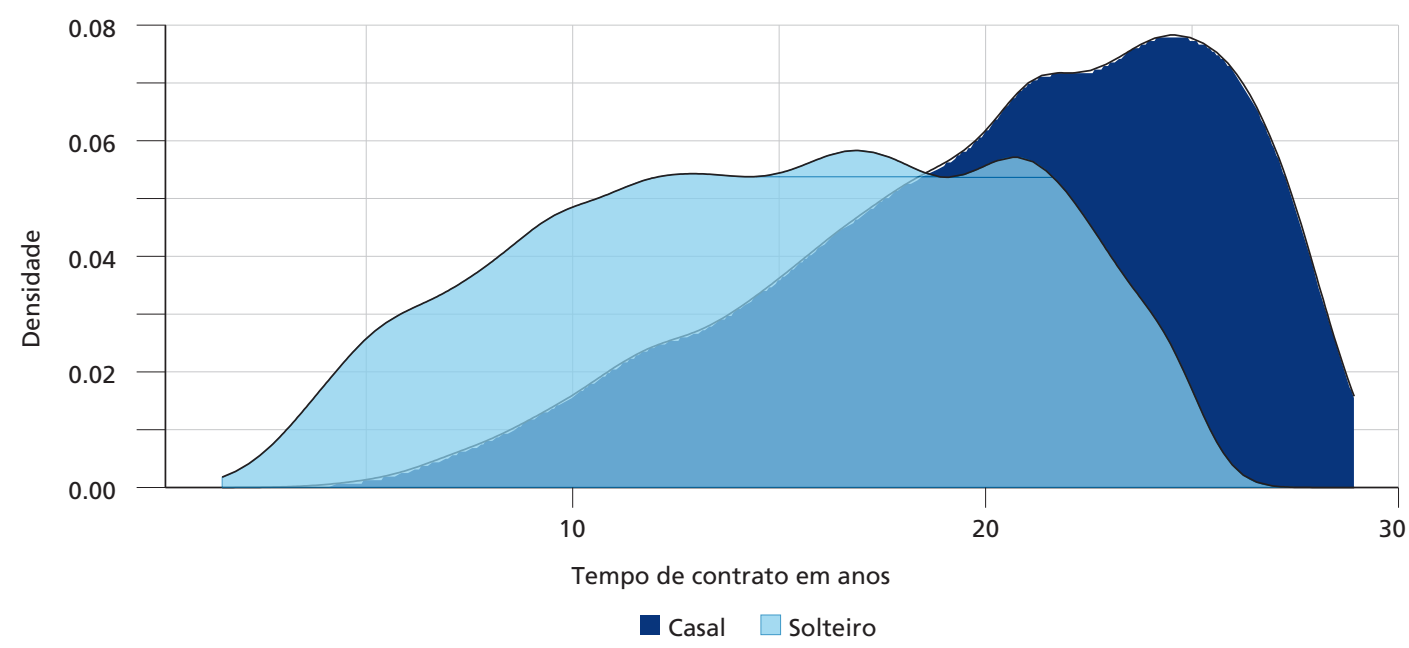

Elaboração dos autores.

B.1D - Volume anual de BHR para os contratos dos domicílios elegíveis atuais encontrados na PNAD por tipo de contrato

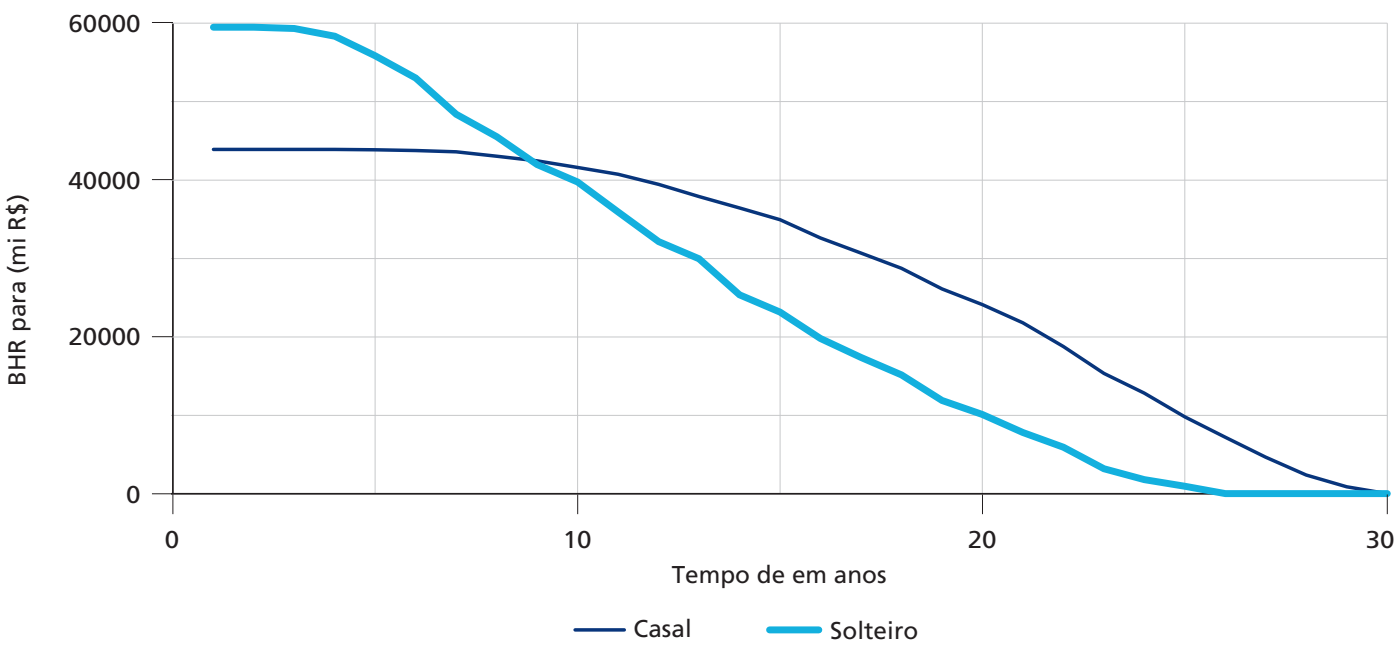

Elaboração dos autores. 
B.1E - Distribuição observada para log do BHR dos domicílios elegíveis encontrados na PNAD por tipo de contrato, segundo existência de benefício BPC

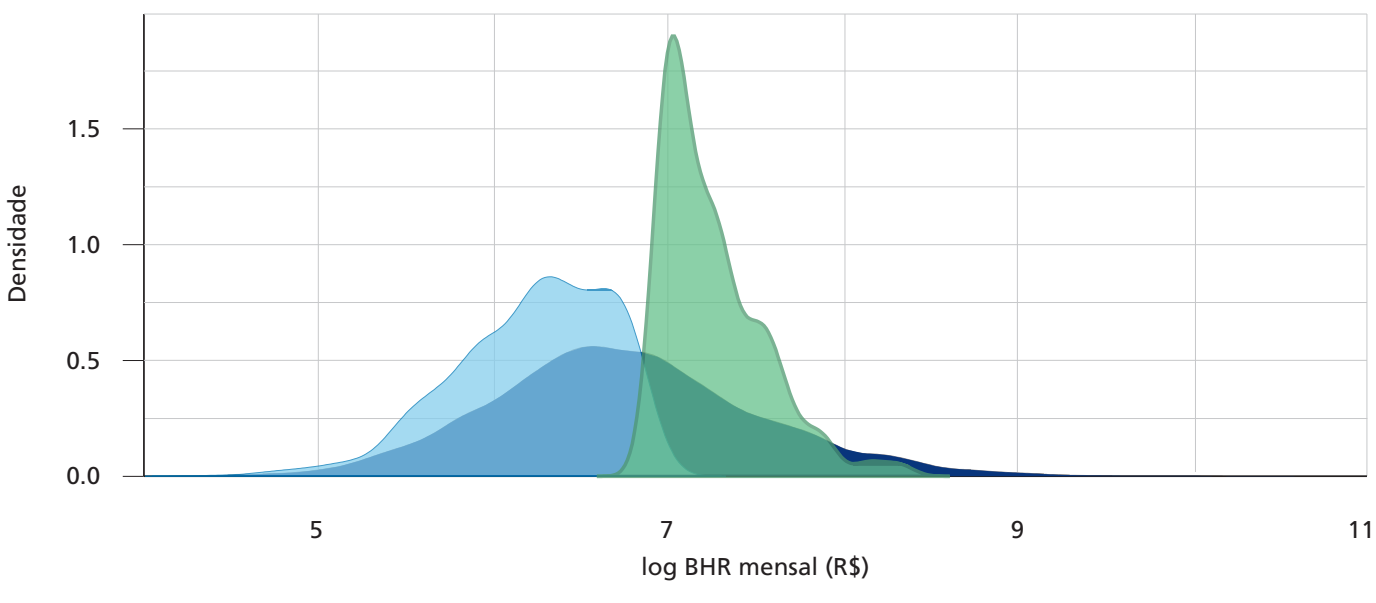

Geral $\square$ BPC $\square$ BPCR\$1000

Elaboração dos autores.

B.1F - Distribuição observada para log do VI dos domicílios elegíveis encontrados na PNAD por tipo de contrato, segundo existência de benefício BPC

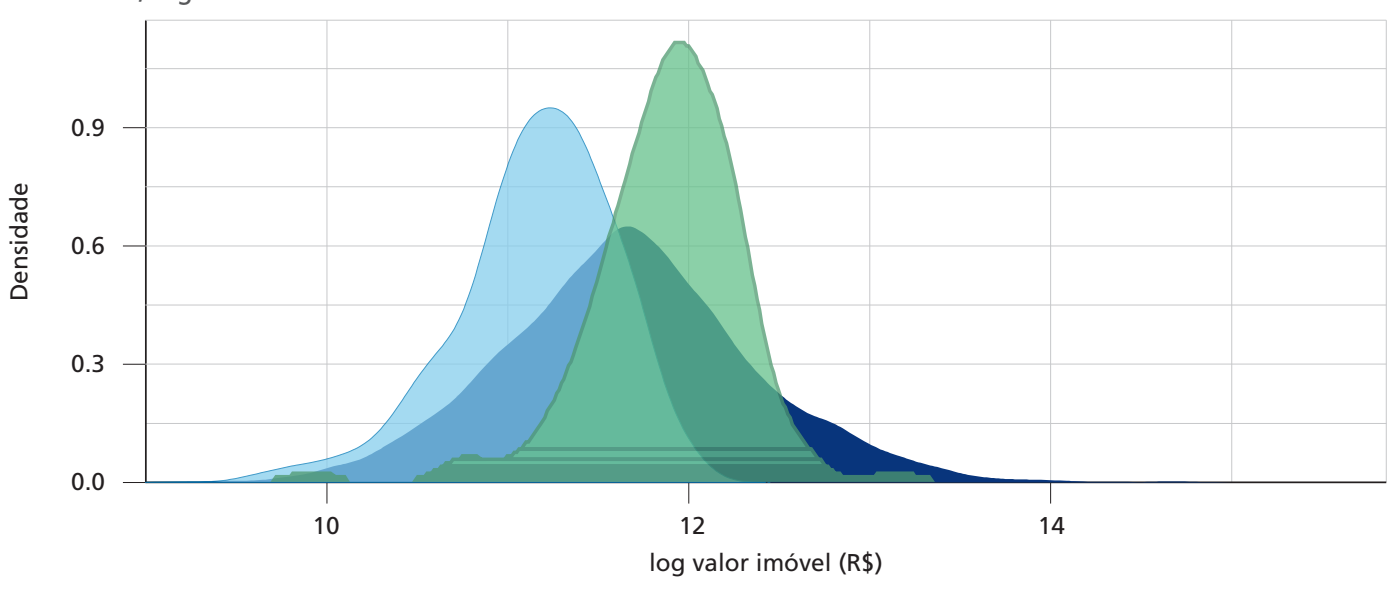

Elaboração dos autores. 
B.1G - Distribuição observada para o tempo esperado do contrato dos domicílios elegíveis encontrados na PNAD por tipo de contrato, segundo existência de benefício BPC

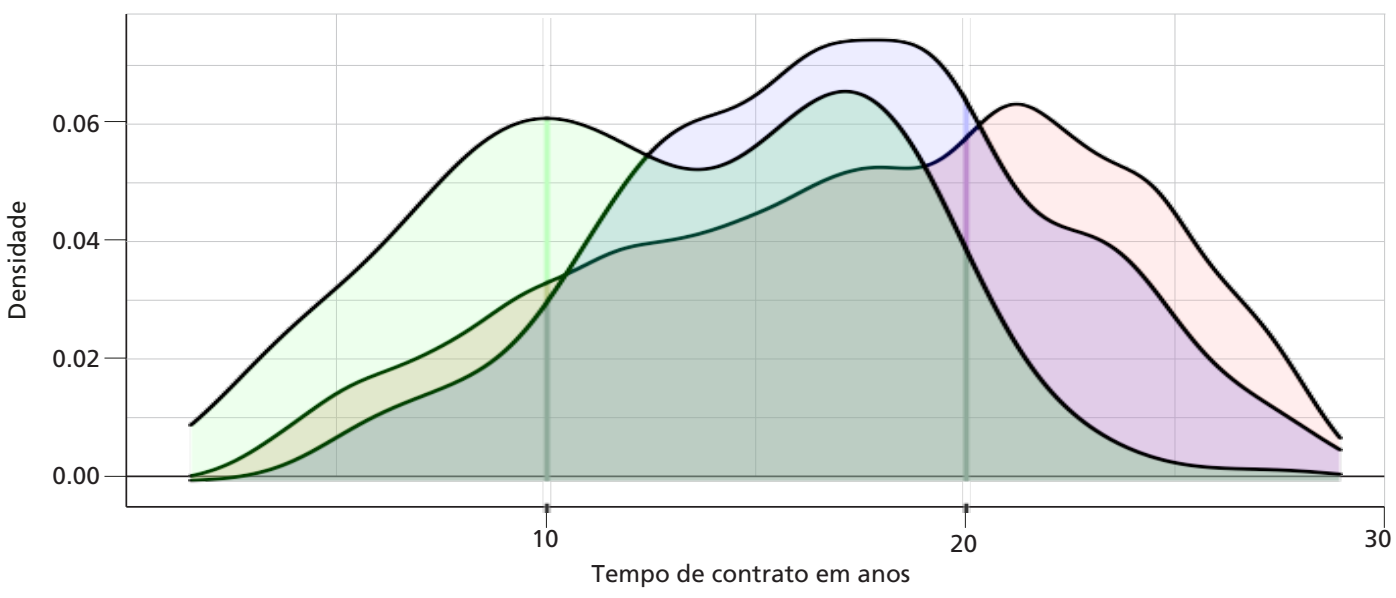

Geral $\square$ BPC $\square$ BPCR\$1000

Elaboração dos autores.

B.1 $\mathrm{H}$ - Volume anual de BHR para os contratos dos domicílios elegíveis atuais encontrados na PNAD por tipo de contrato, segundo existência de benefício BPC

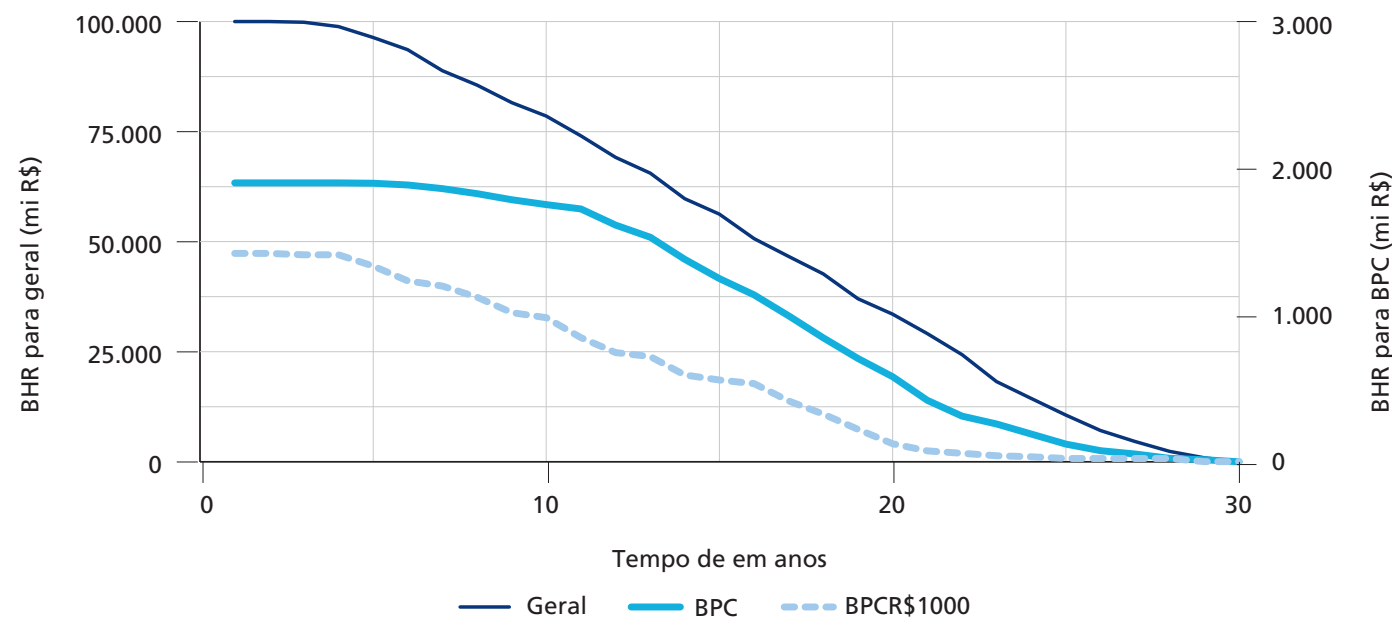

Elaboração dos autores.

Obs.: 1. BHR - benefício de hipoteca reversa; PNAD - Pesquisa Nacional por Amostra de Domicílios; VI - valor do imóvel; e BPC - Benefício de Prestação Continuada. 2. BPC R\$ 1 mil indica lares com benefício BHR superior a R\$ 1 mil. 


\section{APÊNDICE C}

\section{TEMPO ESPERADO DE VIGÊNCIA DE CONTRATO}

\section{TABELA C.1}

Expectativa para o tempo de contrato para algumas idades considerando tábua por sexo e para a tábua para o casal com mesma idade baseada na tábua RP-2000

\begin{tabular}{|c|c|c|c|}
\hline Idade & Expectativa casal & Expectativa homem & Expectativa mulher \\
\hline 60 & 28,91 & 22,55 & 24,58 \\
\hline 61 & 27,94 & 21,67 & 23,70 \\
\hline 62 & 26,99 & 20,80 & 22,83 \\
\hline 63 & 26,05 & 19,95 & 21,97 \\
\hline 64 & 25,13 & 19,11 & 21,12 \\
\hline 65 & 24,20 & 18,29 & 20,30 \\
\hline 66 & 23,28 & 17,48 & 19,48 \\
\hline 67 & 22,38 & 16,69 & 18,68 \\
\hline 68 & 21,49 & 15,91 & 17,89 \\
\hline 69 & 20,59 & 15,15 & 17,12 \\
\hline 70 & 19,72 & 14,39 & 16,36 \\
\hline 71 & 18,86 & 13,65 & 15,62 \\
\hline 72 & 18,02 & 12,92 & 14,89 \\
\hline 73 & 17,16 & 12,21 & 14,17 \\
\hline 74 & 16,33 & 11,52 & 13,47 \\
\hline 75 & 15,52 & 10,84 & 12,79 \\
\hline 76 & 14,72 & 10,18 & 12,11 \\
\hline 77 & 13,95 & 9,54 & 11,46 \\
\hline 78 & 13,15 & 8,92 & 10,82 \\
\hline 79 & 12,40 & 8,33 & 10,20 \\
\hline 80 & 11,67 & 7,75 & 9,59 \\
\hline 81 & 10,95 & 7,21 & 9,01 \\
\hline 82 & 10,27 & 6,69 & 8,44 \\
\hline 83 & 9,60 & 6,21 & 7,89 \\
\hline 84 & 8,97 & 5,74 & 7,36 \\
\hline 85 & 8,35 & 5,31 & 6,85 \\
\hline
\end{tabular}


Texto para

Discussão

2620 Dimensionando o Mercado para Hipoteca Reversa no Brasil

\section{ANEXO A}

QUADRO A.1

Dicionário das variáveis utilizadas

\begin{tabular}{|c|c|c|c|}
\hline Variável & Descrição & Tipo & Descrição \\
\hline \multirow{27}{*}{ UF } & \multirow{27}{*}{ Unidade da Federação (UF) } & 11 & Rondônia \\
\hline & & 12 & Acre \\
\hline & & 13 & Amazonas \\
\hline & & 14 & Roraima \\
\hline & & 15 & Pará \\
\hline & & 16 & Amapá \\
\hline & & 17 & Tocantins \\
\hline & & 21 & Maranhão \\
\hline & & 22 & Piauí \\
\hline & & 23 & Ceará \\
\hline & & 24 & Rio Grande do Norte \\
\hline & & 25 & Paraíba \\
\hline & & 26 & Pernambuco \\
\hline & & 27 & Alagoas \\
\hline & & 28 & Sergipe \\
\hline & & 29 & Bahia \\
\hline & & 31 & Minas Gerais \\
\hline & & 32 & Espírito Santo \\
\hline & & 33 & Rio de Janeiro \\
\hline & & 35 & São Paulo \\
\hline & & 41 & Paraná \\
\hline & & 42 & Santa Catarina \\
\hline & & 43 & Rio Grande do Sul \\
\hline & & 50 & Mato Grosso do Sul \\
\hline & & 51 & Mato Grosso \\
\hline & & 52 & Goiás \\
\hline & & 53 & Distrito Federal \\
\hline UPA & Unidade Primária de Amostragem (UPA) & & UF (2) + Número sequencial (6) + DV (1) \\
\hline Estrato & & & As duas primeiras posições representam o código da UF \\
\hline V1008 & Número de seleção do domicílio & 1 a 14 & Número do domicílio \\
\hline V1014 & Painel & 1 a 99 & Grupo de amostra \\
\hline \multirow{2}{*}{ V1022 } & \multirow{2}{*}{ Situação do domicílio } & 1 & Urbana \\
\hline & & 2 & Rural \\
\hline
\end{tabular}


Brasília, dezembro de 2020

\begin{tabular}{|c|c|c|c|}
\hline Variável & Descrição & Tipo & Descrição \\
\hline \multirow{4}{*}{ V1023 } & \multirow{4}{*}{ Tipo de área } & 1 & Capital \\
\hline & & 2 & Resto da região metropolitana (RM), excluindo a capital \\
\hline & & 3 & $\begin{array}{l}\text { Resto da região integrada de desenvolvimento econômico } \\
\text { (Ride), excluindo a capital }\end{array}$ \\
\hline & & 4 & Resto da UF, excluindo a RM e a Ride \\
\hline V1032 & Peso do domicílio e das pessoas & $\begin{array}{l}6 \text { dígitos e } 8 \text { casas } \\
\text { decimais }\end{array}$ & $\begin{array}{l}\text { Peso anual de primeira visita com correção de não entrevista } \\
\text { com pós-estratificação pela projeção de população }\end{array}$ \\
\hline \multirow{19}{*}{ V2005 } & \multirow{19}{*}{ Condição no domicílio } & 1 & Pessoa responsável pelo domicílio \\
\hline & & 2 & Cônjuge ou companheiro(a) de sexo diferente \\
\hline & & 3 & Cônjuge ou companheiro(a) do mesmo sexo \\
\hline & & 4 & Filho(a) do responsável e do cônjuge \\
\hline & & 5 & Filho(a) somente do responsável \\
\hline & & 6 & Enteado(a) \\
\hline & & 7 & Genro ou nora \\
\hline & & 8 & Pai, mãe, padrasto ou madrasta \\
\hline & & 9 & Sogro(a) \\
\hline & & 10 & Neto(a) \\
\hline & & 11 & Bisneto(a) \\
\hline & & 12 & Irmão ou irmã \\
\hline & & 13 & Avô ou avó \\
\hline & & 14 & Outro parente \\
\hline & & 15 & Agregado(a) - não parente que não compartilha despesas \\
\hline & & 16 & Convivente - não parente que compartilha despesas \\
\hline & & 17 & Pensionista \\
\hline & & 18 & Empregado(a) doméstico(a) \\
\hline & & 19 & Parente do(a) empregado(a) doméstico(a) \\
\hline \multirow{2}{*}{ V2007 } & \multirow{2}{*}{ Sexo } & 1 & Homem \\
\hline & & 2 & Mulher \\
\hline V2009 & Idade do morador na data de referência & 0 a 130 & Idade (em anos) \\
\hline \multirow{2}{*}{ V5001A } & \multirow{2}{*}{$\begin{array}{l}\text { No mês de ... (mês de referência), ... recebeu } \\
\text { rendimentos de Benefício Assistencial de Presta- } \\
\text { ção Continuada - BPC-LOAS? }\end{array}$} & 1 & Sim \\
\hline & & 2 & Não \\
\hline \multirow{3}{*}{ S01001 } & \multirow{3}{*}{ Este domicílio é do tipo: } & 1 & Casa \\
\hline & & 2 & Apartamento \\
\hline & & 3 & Habitação em casa de cômodos, cortiço ou cabeça de porco \\
\hline \multirow{6}{*}{ S01002 } & \multirow{6}{*}{$\begin{array}{l}\text { Qual é o material que predomina na construção } \\
\text { das paredes externas deste domićlío? }\end{array}$} & 1 & Alvenaria com revestimento/taipa com revestimento \\
\hline & & 2 & Alvenaria sem revestimento \\
\hline & & 3 & Taipa sem revestimento \\
\hline & & 4 & Madeira apropriada para construção (aparelhada) \\
\hline & & 5 & Madeira aproveitada \\
\hline & & 6 & Outro material \\
\hline
\end{tabular}


Texto para

Discussão

2620 Dimensionando o Mercado para Hipoteca Reversa no Brasil

\begin{tabular}{|c|c|c|c|}
\hline Variável & Descrição & Tipo & Descrição \\
\hline \multirow{6}{*}{ S01003 } & \multirow{6}{*}{$\begin{array}{l}\text { Qual é o material que predomina na cobertura } \\
\text { (telhado) deste domicilio? }\end{array}$} & 1 & Telha sem laje de concreto \\
\hline & & 2 & Telha com laje de concreto \\
\hline & & 3 & Somente laje de concreto \\
\hline & & 4 & Madeira apropriada para construção \\
\hline & & 5 & Zinco, alumínio ou chapa metálica \\
\hline & & 6 & Outro material \\
\hline \multirow{5}{*}{ S01004 } & \multirow{5}{*}{$\begin{array}{l}\text { Qual é o material que predomina no piso deste } \\
\text { domicílio? }\end{array}$} & 1 & Cerâmica, lajota ou pedra \\
\hline & & 2 & Madeira apropriada para construção \\
\hline & & 3 & Cimento \\
\hline & & 4 & Terra \\
\hline & & 5 & Outro material \\
\hline S01005 & Quantos cômodos tem este domicílio? & 1 a 30 & Cômodo(s) no domicílio \\
\hline S01006 & $\begin{array}{l}\text { Quantos cômodos estão servindo permanente- } \\
\text { mente de dormitório para os moradores deste } \\
\text { domicílio? }\end{array}$ & 1 a 15 & Cômodo(s) servindo de dormitório \\
\hline \multirow{3}{*}{ S01009 } & \multirow{3}{*}{$\begin{array}{l}\text { Este domićlio dispõe ou faz uso de reservatório, } \\
\text { caixa d'água, cisterna, para armazenar a água? }\end{array}$} & 1 & Sim \\
\hline & & 2 & Não \\
\hline & & & Não aplicável \\
\hline S01011A & $\begin{array}{l}\text { Quantos banheiros (com chuveiro ou banheira e } \\
\text { vaso sanitário ou privada) de uso exclusivo dos } \\
\text { moradores existem neste domicílio, inclusive os } \\
\text { localizados no terreno ou na propriedade? }\end{array}$ & 0 a 15 & $\begin{array}{l}\text { banheiro(s) com chuveiro (ou banheira) e vaso sanitário (ou } \\
\text { privada) }\end{array}$ \\
\hline \multirow{7}{*}{ S01012A } & \multirow{7}{*}{$\begin{array}{l}\text { Para aonde vai o esgoto do banheiro (sanitário } \\
\text { ou buraco de dejeção)? }\end{array}$} & 1 & Rede geral, rede pluvial \\
\hline & & 2 & Fossa séptica ligada à rede \\
\hline & & 3 & Fossa séptica não ligada à rede \\
\hline & & 4 & Fossa rudimentar \\
\hline & & 5 & Vala \\
\hline & & 6 & Rio, lago ou mar \\
\hline & & & Não aplicável \\
\hline \multirow{6}{*}{ S01013 } & \multirow{6}{*}{ Qual é o (principal) destino dado ao lixo? } & 1 & Coletado diretamente por serviço de limpeza \\
\hline & & 2 & Coletado em caçamba de serviço de limpeza \\
\hline & & 3 & Queimado (na propriedade) \\
\hline & & 4 & Enterrado (na propriedade) \\
\hline & & 5 & Jogado em terreno baldio ou logradouro \\
\hline & & 6 & Outro destino \\
\hline \multirow{3}{*}{ S01014 } & \multirow{3}{*}{$\begin{array}{l}\text { Qual(is) a(s) origem(ns) da energia elétrica } \\
\text { utilizada neste domićlio? }\end{array}$} & 1 & Utiliza ao menos uma fonte de energia elétrica \\
\hline & & 2 & Não utiliza/tem energia elétrica \\
\hline & & & Não aplicável \\
\hline
\end{tabular}


Brasília, dezembro de 2020

\begin{tabular}{|c|c|c|c|}
\hline Variável & Descrição & Tipo & Descrição \\
\hline \multirow{7}{*}{ S01017 } & \multirow{7}{*}{ Este domicílio é: } & 1 & Próprio de algum morador - já pago \\
\hline & & 2 & Próprio de algum morador - ainda pagando \\
\hline & & 3 & Alugado \\
\hline & & 4 & Cedido por empregador \\
\hline & & 5 & Cedido por familiar \\
\hline & & 6 & Cedido de outra forma \\
\hline & & 7 & Outra condição \\
\hline \multirow{2}{*}{ S01019 } & \multirow{2}{*}{$\begin{array}{l}\text { Qual foi o valor mensal do aluguel pago, ou que } \\
\text { deveria ter sido pago, no mês de referência? }\end{array}$} & Valor em reais & $\mathrm{R} \$$ \\
\hline & & & Não aplicável \\
\hline \multirow{2}{*}{ S01022 } & \multirow{2}{*}{ Este domicílio tem telefone fixo convencional? } & 1 & Sim \\
\hline & & 2 & Não \\
\hline
\end{tabular}

Fonte: Dicionário da PNAD Contínua/IBGE para 2019. 

Ipea - Instituto de Pesquisa Econômica Aplicada

\section{Assessoria de Imprensa e Comunicação}

\section{EDITORIAL}

\section{Chefe do Editorial}

Reginaldo da Silva Domingos

\section{Assistentes da Chefia}

Rafael Augusto Ferreira Cardoso

Samuel Elias de Souza

\section{Supervisão}

Camilla de Miranda Mariath Gomes

Everson da Silva Moura

\section{Editoração}

Aeromilson Trajano de Mesquita

Cristiano Ferreira de Araújo

Danilo Leite de Macedo Tavares

Herllyson da Silva Souza

Jeovah Herculano Szervinsk Junior

Leonardo Hideki Higa

\section{Capa}

Danielle de Oliveira Ayres

Flaviane Dias de Sant'ana

\section{Projeto Gráfico}

Renato Rodrigues Bueno

The manuscripts in languages other than Portuguese published herein have not been proofread.

\section{Livraria Ipea}

SBS - Quadra 1 - Bloco J - Ed. BNDES, Térreo

70076-900 - Brasília - DF

Tel.: (61) 2026-5336

Correio eletrônico: livraria@ipea.gov.br 

Composto em adobe garamond pro 12/16 (texto) Frutiger 67 bold condensed (títulos, gráficos e tabelas) Brasilia-DF 



\section{Missão do Ipea}

Aprimorar as políticas públicas essenciais ao desenvolvimento brasileiro por meio da produção e disseminação de conhecimentos e da assessoria ao Estado nas suas decisões estratégicas.

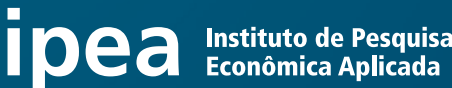 \\ MINISTÉRIO DA \\ ECONOMIA

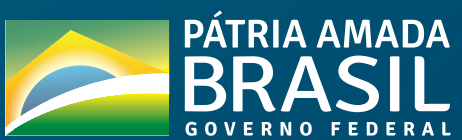

